UNIVERSIDADE DE SÃO PAULO

FACULDADE DE SAÚDE PÚBLICA

DEPARTAMENTO DE EPIDEMIOLOGIA

\title{
VIOLÊNCIA DOMÉSTICA CONTRA IDOSOS NO MUNICÍPIO DE SÃO PAULO - ESTUDO SABE, 2000
}

Dissertação apresentada para defesa do Mestrado no Departamento de Epidemiologia da Faculdade de Saúde Pública da USP.

Aluna: ANA PAULA REOLON AMADIO SANCHES

Orientadora: Prof ${ }^{a}$ Tit. MARIA LÚCIA LEBRÃO 
Todo trabalho de pesquisa envolve a participação de muitas pessoas...

Com este não foi diferente. São muitas pessoas a agradecer, desde a Profa Maria Lúcia que acreditou em mim, mesmo nas horas mais complicadas; a Yeda, que sempre acudiu meus momentos de desalentos; - Fernão "amigo", que me socorria com as tabelas e mais tabelas; a Naide, a Simone e a Marília parceiras de muitas conversas...

O Prof. Jair, sempre com boas sugestões, as Profas Maria Helena e Lilia que contribuíram muito para o desenvolvimento do estudo. datas...

Não poderia me esquecer da Beth, que lembrava os prazos e

A lista é grande, talvez falhe na memória, mas sem dúvida caberá para sempre no meu coração.

Bem, enfim, mais uma etapa encerrada, graças ao empenho que meus pais sempre fizeram em meus estudos, com o colo da $D^{a}$ Teresa e do Sr. Germano que nunca faltaram. Sem esquecer da fiel escudeira Scully, que dormiu muito em meus pés durante a finalização desse trabalho.

Edu querido, essa vitória também é sua. Obrigada por me fazer acreditar! 
ÍNDICE 
1. Introdução

1.1. Envelhecimento Populacional

1.2. Violência contra Idosos

2. Objetivos

2.1. Objetivo Geral

2.2. Objetivos Específicos

3. Metodologia

3.1. O Estudo SABE

3.2. Metodologia utilizada no Estudo da Violência Doméstica contra Idosos

4. Resultados e Discussão

5. Conclusão

6. Referências

ANEXO A: Comitê de Ética da Faculdade de Saúde Pública da Universidade de São Paulo e pela Comissão Nacional de Ética em Pesquisa - CONEP

ANEXO B: Questionário Estudo SABE 
No período de 1997 a 2003 a Organização Pan Americana de Saúde (OPAS) coordenou um estudo multicêntrico denominado SABE Saúde, Bem-Estar e Envelhecimento - para traçar o perfil dos idosos na América Latina e no Caribe.

Com o envelhecimento da população, pesquisas são desenvolvidas nesse tema. A questão da violência doméstica contra idosos tem se ampliado e sugere necessidade de maior campo de investigação nessa área.

O objetivo deste estudo foi verificar os possíveis sinais de violência observados pelas entrevistadoras do Estudo SABE, realizado em São Paulo, composto pelos idosos residentes no ano de 2000, na área urbana do município.

Os dados demonstram que os idosos com suposta condição de violência no Estudo SABE caracterizam-se por idade avançada, baixa escolaridade, sexo feminino e estado civil solteiro, entre outras variáveis aqui apresentadas.

Ao considerar esses dados levantados e o Censo de 2000 de 972.199 pessoas idosas em São Paulo, atualmente há uma projeção de 12.638 idosos possíveis vítimas de violência doméstica. Esses resultados apontam para a necessidade de maiores estudos nesse campo, vista a relevância da questão da violência contra a população idosa e a importância da formulação de políticas públicas que visem a proteger esta faixa da população. 
ABSTRACT 
In the period from 1997 to 2003 the Organization American Pan of Health (OPAS) it coordinated a study denominated multicentric SABE Health, Well-being and Aging - to draw the seniors' profile in Latin America and in Caribbean.

With the aging of the population, researches are developed in that theme. The subject of the domestic violence against seniors has if enlarged and suggests need of larger investigation field in that area.

The objective of this study was to verify the possible violence signs observed by the interviewers of the Study SABE, accomplished in São Paulo, composed by the resident seniors in the year of 2000 , in the urban area of the municipal district.

The data demonstrate that the seniors with having supposed violence condition in the Study SABE, they are characterized by advanced age, low education, feminine sex and single marital status, among other variables here presented.

When considering those lifted up data and the Census of 2000 of 972.199 senior people in São Paulo, now there is a projection of 12.638 possible senior victims of domestic violence. Those results appear for the need of larger studies in that field, seen the relevance of the subject of the violence against the senior population and the importance of the formulation of public politics that seek to protect this strip of the population. 


\subsection{Envelhecimento Populacional}

Atualmente, um dos assuntos pesquisados na área de Epidemiologia é o processo de transição demográfica pelo qual o Brasil passa, definido por pesquisadores em estudos passados e previsto por Ramos ${ }^{(1)}$, em 1987, como um possível "boom" de idosos na população brasileira para as próximas décadas.

Há tempos se falava desse processo na Europa e suas mudanças na sociedade em todos os aspectos. Agora, essa situação é vivida num país que faz sua transição em espaço de tempo comprimido, mas com a urgência de uma população que vivencia o impacto dessa situação e não sabe como lidar com a questão do envelhecimento.

Paralela à questão do envelhecimento, há a redução do número de filhos por casal, diminuindo o desenvolvimento da população ativa.

Berquó(2), em seus estudos, esclarece que a taxa de reposição de filhos por casal mínima e ideal para a população não envelhecer demasiadamente é de 2,1 filhos/mulher.

Em agosto de 2005, o Instituto Brasileiro de Geografia e Estatística (IBGE) $^{(3)}$ publicou a Revisão 2004 da Projeção da População, onde observa que, em 2004, essa taxa era de 2,3 filhos por mulher e em 2023 deverá atingir a taxa de 2,0 filhos por mulher.

Assim, com a projeção do IBGE, será atingida a taxa mínima de reposição filhos por mulher.

Nesta mesma Revisão, o IBGE aponta que em 2050 o país atingirá o número de 259,8 milhões de brasileiros, com uma expectativa de vida ao nascer de 81,3 anos, demonstrando um envelhecimento acentuado da população, que em 2000 tinha $30 \%$ de jovens entre 0 e 14 anos, em relação aos $5 \%$ de pessoas com 65 anos e mais. Segundo o IBGE, em 2050 estes dois grupos se igualarão em 18\%.

Assim, é sugerido, nesta Revisão, o desenvolvimento de políticas de saúde voltadas para a Terceira Idade, pois se em 2000 o Brasil tinha 1,8 milhão de pessoas com 80 anos ou mais, em 2050, o número será de 13,7 milhões somente para essa faixa etária. 
Em dezembro de 2005, o IBGE ${ }^{(4)}$ divulgou a Tábua de Vida para a população onde confirma esses dados, demonstrando que a expectativa média de vida do indivíduo nascido em 2004 aumentou para 71,7 anos, o que representa um acréscimo de 4 meses e 24 dias em relação a 2003; sendo que nos últimos 25 anos esse aumento foi de 9,1 anos. Embora seja claro que tal avanço, comparado a outros países, ainda é pouco considerável, já que essa expectativa varia conforme o local de nascimento do indivíduo, fruto da desigualdade social ainda importante no país.

Essa previsão do envelhecimento populacional também foi demonstrada pela Organização Mundial de Saúde $(\mathrm{OMS})^{(5)}$, que refere uma população de 60 anos e mais passando de 542 milhões em 1995, para 1,2 bilhão em 2025. Os estudos de Kalache et $a^{(6)}$ relatam que o aumento da população idosa será da ordem de quinze vezes, entre 1950 e 2025, enquanto o aumento da população total neste mesmo período não ultrapassará cinco vezes.

Neri ${ }^{(7)}$ ressalta, em seu trabalho, o quanto é grave o problema do envelhecimento no Brasil pois essa população está crescendo rapidamente e os idosos são considerados ônus para a sociedade. Assim, o que deveria ser comemorado, já que se vive mais hoje em dia, passa a ser motivo de entristecimento e questionamento.

É importante refletir que o envelhecimento populacional não se refere às pessoas, nem às gerações, mas sim, à mudança na estrutura etária da população, produzindo um aumento das pessoas acima de determinada idade, considerada como definidora do início da velhice (Carvalho $\left.{ }^{8}\right)$, na sociedade brasileira marcada pelos 60 anos de vida.

A Organização Pan-Americana de Saúde (PAHO) relata a necessidade e importância de pesquisas considerando essa nova estrutura etária da população sempre incentivando o desenvolvimento dessa temática ${ }^{(9)}$.

Em 2003, Veras ${ }^{(10)}$ publicou estudo demonstrando a importância desse assunto para a área de saúde, um dos aspectos mais afetados pelo envelhecimento populacional abrupto. Em seu estudo, Veras apresenta um grupo de 306 indivíduos onde $11 \%$ têm de médio a alto risco de 
adoecer e, consequentemente, onerar o sistema de saúde pública, com intuito de mostrar, assim, a necessidade de classificação de grupos de risco para fragilidade e como lidar com tal questão.

O mesmo autor fala da longevidade humana em um Brasil que, no início do século 20 , tinha uma expectativa de vida ao nascer em média de 33 anos e hoje conta com os recursos médico-tecnológicos que levam o relógio biológico dos indivíduos a atingir 90 ou 95 anos, sendo estimado para as próximas décadas por volta de 130 anos. Com a consideração, ainda, de que, embora atualmente seja desafio, os avanços científicos e tecnológicos possibilitarão ao idoso alcançar esse limite etário de forma independente e sadia.

Toda a sociedade, como dito por Carvalho ${ }^{(8)}$, nessa nova estrutura etária, deverá ser adaptada e reorganizar seus serviços para atendimento dessa demanda: aposentadoria aos 60 anos, mas com início de um novo ciclo produtivo, com duração de mais 30 anos; cursos universitários para a terceira idade; serviços específicos para o maior número de mulheres idosas e viúvas; medicamentos para tratamento mais ampliado da esfera sexual dessa população envelhecida e ativa; e famílias multigeracionais, tendo o idoso o papel de provedor com sua aposentadoria $\left(\right.$ Veras $\left.^{10}\right)$.

Enfim, a conscientização de que envelhecer será um processo ao qual todos vivenciarão, portanto, deve ser passível de planejamento e atenção das políticas públicas.

\subsection{Violência contra idosos}

Ao se estudar o envelhecimento humano verificam-se questões relativas à violência contra idosos, desde épocas antigas.

Hudson $^{(11)}$, em seus estudos, analisa a possibilidade de a violência intra familiar ocorrer desde os primórdios da humanidade, tendo variações para culturas e sociedades diferentes. Refere que muitos estudos documentam a existência de violência contra os idosos, mas não trazem clareza nas informações antecedentes para causas e conseqüências das situações avaliadas. 
Historicamente, envelhecer era sinônimo de vida abastada, pois os pobres raramente chegavam à velhice. Entre as sociedades ${ }^{(12)}$ verificamse diferentes reações ao envelhecimento humano, como os esquimós, que trabalhavam até o momento em que não conseguiam mais prover a si mesmos; então esse era o momento de cometer o suicídio, pois pessoas incapacitadas e velhas para a vida normal deveriam desaparecer dessa sociedade.

No Himalaia, as famílias são patriarcais, sobrevivem de seu trabalho na lavoura e sabem ler. Nessa comunidade, as famílias são respeitadas e possuem papéis multigeracionais bem definidos, zelando pelos seus idosos, mas se o idoso não souber ler ou não tiver filhos, a sociedade o desprezará e ele contará apenas com o apoio de sua própria família para viver.

Os cunas, no Panamá, são reunidos em grupos, onde o marido da mais velha das irmãs atua como chefe de família; porém, nenhum benefício é concedido pela idade, e sim pela inteligência e experiência. $O$ chefe da família será mantido enquanto tiver capacidade para tal, o fator idade não condiciona a nenhum posto de autoridade entre os membros da família.

Em algumas tribos, como os Jahgares, que habitavam o sul da Argentina, o respeito ao idoso existia e o mesmo era consultado pelos mais jovens sobre suas decisões.

O mesmo é observado na tribo indígena Caiapós, no Brasil, onde apenas um clã tem o direito de usar o botoque (disco labial de madeira), os membros que formam o Conselho dos Velhos, cuja principal tarefa é estabelecer regras para o comportamento político e social da comunidade.

Nas civilizações antigas, os Incas, até os 50 anos eram ativos, podendo ser recrutados para o exército ou serviços comunitários. A partir dos 80 anos, executavam tarefas de pequeno porte, porém eram temidos e obedecidos por todos, tendo poder, inclusive, para castigar crianças desobedientes. Cabia ao Estado não Ihes cobrar impostos, fornecer gratuitamente comida, roupa, remédios e moradia até a sua morte. 
Entre os Vikings, as famílias eram compostas por três gerações: avós, pais e filhos. Embora o convívio fosse grupal e todos se ajudassem mutuamente, numa situação de crise, idosos e recém-nascidos eram abandonados, pois o mantimento existente era destinado aos mais jovens e saudáveis, os mantenedores dos grupos.

A sociedade dos Balineses tinha papéis definidos, mas com o passar do tempo, as tarefas dos idosos aumentavam devido ao respeito e experiência que acumulavam; as mulheres cuidavam da família que crescia, os homens não exerciam trabalhos físicos, mas assumiam papel de médico, contador de histórias, eram sacerdotes honorários dos templos e opinavam sobre o rumo da aldeia.

Entre os Russos, o provérbio "onde estão os cabelos brancos está a razão"(12) direcionava a comunidade à obediência ao chefe da família, que era o respeito pelos seus anciãos. As mulheres idosas guiavam as tarefas domésticas e dividiam com as mulheres mais jovens. As idosas não tinham direito à herança paterna, somente os homens que também eram responsáveis pela assistência aos pais idosos.

Na civilização islâmica, os árabes idosos eram conhecidos pela sua consciência, por seu alto padrão moral e pelo conhecimento profundo dos assuntos da sociedade, sendo respeitados como mestres.

Confúcio, filósofo da Antiga China, já dizia da importância do elemento mais idoso nas famílias, valorizando sua experiência e sabedoria ${ }^{(12)}$ pois, em algumas sociedades tradicionais do passado, a harmonia em família era reforçada pela tradição e políticas públicas, como na sociedade chinesa onde a "reverência era incutida por um sistema de valores que ressaltava a piedade filial ${ }^{p(5)}$, sendo assim desconhecidos atos de violência aos idosos naquela época; na sociedade japonesa o idoso fazia parte de um grupo superior, sendo que todos deveriam ser sacrificados pelo bem estar desse grupo.

Nos dias atuais essa situação não mais é verídica. Kalache ${ }^{(13)}$ refere que, na época atual até a sociedade japonesa não mais vê seus idosos dessa forma, tendo sucumbido, também, aos atos de violência contra os mesmos. 
Uchoa ${ }^{(14)}$, em estudo sobre antropologia e contribuições para a saúde do idoso, mostra diferentes exemplos do relacionamento dos idosos com sua comunidade, onde se encontram relações de valorização e respeito, como no grupo Bambara do Mali, que considera a velhice um ganho, uma fase da vida a ser conquistada que traz enobrecimento ao ser humano; ou os Nuer, grupo étnico do Sudão, que realiza um ritual de entrada na adolescência, a fim de marcar as diferentes etapas do desenvolvimento masculino, onde um grupo deve respeito ao grupo anterior de desenvolvimento, que é composto por pessoas mais velhas.

Esse mesmo autor refere, ainda, relatos de situações onde o envelhecimento não é bem aceito, como o paradoxo existente entre os membros do grupo Inuit (esquimós) que, ao mesmo tempo, demonstram carinho e afeição aos indivíduos mais velhos de sua comunidade, mas também podem abandoná-los em uma estrada, ou auxiliá-los a cometer suicídios por afogamento ou estrangulamento. Por outro lado, observa a negação do envelhecimento pela sociedade Cuiva, onde os idosos são tratados como se a velhice não existisse, a fim de evitar um processo de ruptura social causado pelo envelhecimento ${ }^{(14)}$.

No relatório mundial sobre violência da $\mathrm{OMS}^{(5)}$, também são encontrados relatos de sociedades tradicionais em algumas partes da África e da Índia, onde mulheres viúvas idosas são abandonadas e suas propriedades são tomadas ou the são infligidas práticas de casamento forçado, violência sexual e expulsão de seus lares. Verifica-se, na África subsaariana, a expulsão de mulheres idosas de seus lares, para viver na pobreza em áreas urbanas, devido à acusação de bruxaria, que também ocorre na República Unida da Tanzânia, onde cerca de 500 mulheres idosas, todos os anos, são assassinadas por esse motivo(15).

Dados mais modernos sobre relatos de violência contra idosos datam de trinta anos atrás, em 1975, na Inglaterra, citados por Baker (apud Minayo ${ }^{16}$ ), que descreveu o "espancamento dos avós" e no Brasil, bem mais recente, em 1997, referidos por Minayo ${ }^{(16)}$, sugerindo a necessidade de estudos nesse tema.

É interessante verificar que não só a produção de pesquisas na temática é de grande importância, mas também, a criação e 
aperfeiçoamento de leis que sejam pertinentes a esses casos de violência, assim como existiu o desenvolvimento desse aspecto para vitimização da mulher e da criança.

Sousa ${ }^{(12)}$ coloca a importância do desenvolvimento de leis que atendam à necessidade e garantam o direito dessa faixa etária da população que está se ampliando, pois é dever do Estado e da família a manutenção de uma velhice digna aos seus idosos, preferencialmente no âmbito familiar. A mesma autora atenta para o dever do Direito em conscientizar e normatizar a família do seu papel em relação à tutela jurídica e amparo desses idosos, uma vez que o Estado não poderá oferecer tal condição, optando pelo contexto institucional, afastando-o de sua família.

A autora chama a atenção, ainda, para a dificuldade em nomear essa faixa de população, que já foram chamados de "velhos", "anciãos", "terceira idade", "melhor idade", mas a Constituição da República no artigo 230, Lei $8842 / 94$ e a Lei 10741/03, cita, como menos pejorativa, a nomenclatura "pessoas idosas" ou "idosos".

Embora toda a complexidade da questão, os idosos têm, desde a Constituição Federal de $1988^{(17)}$, a intenção de proteção legal como no artigo 230 que esclarece: "a família, a sociedade e o Estado têm o dever de amparar as pessoas idosas, assegurando sua participação na comunidade, defendendo sua dignidade e bem-estar e garantindo-Ihes o direito à vida".

Em 1994, a Lei $n^{\circ}$ 8.842, que dispõe sobre a Política Nacional do Idoso, cria o Conselho Nacional do Idoso, que tem por objetivo assegurar os direitos sociais do idoso, fornecendo condições para respeitar sua autonomia, integração e participação efetiva na sociedade ${ }^{(18)}$, sendo que nesta lei, em seu capítulo IV, $\S 3^{\circ}$, fica explícito o dever de todo cidadão denunciar qualquer forma de negligência e maus tratos ao idoso ${ }^{(19)}$.

Ainda nessa lei, artigo 10, fica esclarecido o papel da Justiça (inciso IV) no trato com o idoso: promover e defender os direitos da pessoa idosa, zelar pela aplicação das normas sobre o idoso, determinar ações para evitar abusos e lesões a seus direitos ${ }^{(20)}$. 
A criação do Estatuto do Idoso ${ }^{(21)}$, em 2003, é a mais nova conquista dos idosos, tendo o intuito de regular os direitos assegurados às pessoas com idade superior ou igual a 60 anos, embora ainda passível de análise e aperfeiçoamento.

Desde 1991, a Delegacia do Idoso de São Paulo estava em funcionamento, porém foi com a entrada do Estatuto do Idoso, em vigor em 2004, mais de uma década depois, que os atendimentos foram intensificados ${ }^{(22)}$ : em relação a 2003 , o atendimento foi superado em $99 \%$ e em relação a 2002 o aumento foi de $127 \%$. As queixas ou busca de orientações foram relacionadas a denúncias de maus-tratos, abandono, ameaça ou apropriação indevida de bens materiais. Ainda pelo controle da Delegacia, sabe-se, que nos casos mais graves de denúncias de maus-tratos, abandono ou exploração financeira, os responsáveis, em $90 \%$ dos casos, são familiares próximos, como os filhos e por conta disto, embora os idosos saibam de seus direitos, acabam por retirar a queixa para proteger a família e se protegerem também.

Malagutti(20) discute o atendimento nas Delegacias do Idoso em São Paulo e no Rio de Janeiro, em contraponto com a solução adotada em Brasília, que por meio de lei criou seções especiais ao idoso nas delegacias que já existem, oferecendo condições de atendimento especializado, facilitando acesso aos idosos e economizando na implantação de serviços específicos.

Embora as leis existam, ainda há muito que se elaborar neste iceberg da violência contra o idoso, porque, mais do que leis que amparem o idoso vítima da violência, há por trás disso agressores muitas vezes familiares a esse idoso que, portanto, deveriam ampará-lo nessa situação. Para o idoso pode ser angustiante utilizar as leis para denunciar agressores, muitas vezes, gerados por ele.

Costa et al ${ }^{(23)} \mathrm{em}$ seu estudo, trazem referência à família como uma criação do ser humano e que não basta viver juntos, mas manter a relação profunda de família de plena reciprocidade entre os sexos e as gerações. Porém, o idoso na sua vida familiar nem sempre consegue desempenhar um papel de relevância. 
Siqueira ${ }^{(24)}$ estuda, em seu livro, o Estatuto do Idoso e as leis pertinentes ao idoso, onde relata o artigo 99 do Estatuto que esclarece as implicações legais a quem praticar violência contra idosos: expor a integridade física ou psíquica do idoso a perigo, resulta em pena de dois meses a um ano e multa, com benefício da suspensão condicional. Se a violência relacionar-se a lesão corporal de natureza grave, então a pena será de reclusão de um a quatro anos, mas se resultar em morte, a reclusão será de quatro a 12 anos e, nesse caso, não há benefício da suspensão condicional do processo.

Ainda relata a responsabilidade do profissional da área de saúde que não denunciar situação de violência: pelo artigo 57 , falta de comunicação de crime, a pena é uma multa que varia de $R \$ 500,00$ a $R \$ 3.000,00$, podendo ser dobrada se existir reincidência.

Mas, a questão da denúncia do agressor familiar continua não sendo abordada. Punir com reclusão quem violenta o idoso, muitas vezes, significa prender a única pessoa que pode cuidar desse idoso, se bem orientada.

Em 2002, o Brasil foi citado como um dos exemplos de violência contra o idoso, em artigo de publicação americana ${ }^{(25)}$, onde fala-se da importância de desenvolvimento de pesquisas nessa área, pois sabe-se que de 4 a $6 \%$ dos idosos sofrem violência dentro de sua própria residência, porém esses números são hipóteses, uma vez que não são dados de estudo epidemiológico.

Wolf(26) refere que, mesmo nos Estados Unidos, onde um dos primeiros relatos de situação de violência data do ano de 1966 e considerando que as pesquisas se iniciaram por volta de 1970, a evolução das mesmas foi deficitária em relação à evolução da gravidade do tema estudado.

No estudo de Tatara et $a^{(27)}$, realizado sobre a incidência nacional de violência ao idoso, numa amostra representativa de 20 municípios dos Estados Unidos, com coordenação do National Center on Elder Abuse (NCEA), foram encontrados, aproximadamente, 450.000 idosos que foram submetidos a situações de abuso ou negligência, em ambiente doméstico durante o ano de 1996. Se esse número considerasse os idosos que 
sofrem violência pelo que os pesquisadores chamam de auto-negligência, ou seja, os idosos que são "perigosos para si mesmos", teriam um número de 551.000 idosos vítimas de abuso; a grande maioria mulheres, provavelmente devido ao padrão de envelhecimento feminino que é vivenciado mundialmente, mas com predomínio dos idosos mais idosos, com 80 anos ou mais, que foram submetidos à negligência de duas a três vezes mais do que toda a população idosa. Em quase $90 \%$ dos abusos incidentes, o agressor conhecido era um parente próximo familiar e $2 / 3$ eram os filhos ou cônjuges.

Esses pesquisadores verificaram que os idosos submetidos ao abuso por negligência são, normalmente, deprimidos, confusos ou extremamente fragilizados. Referem, ainda, a dificuldade que existe para identificar esses casos e, quando identificados, outra barreira é para que as pessoas envolvidas possam colaborar com a denúncia, pois teriam que se responsabilizar pelo idoso em questão, demonstrando o impedimento em abordar diretamente esse tema, mesmo nos países com maior estrutura no assunto.

A questão da auto-negligência é um capítulo à parte a ser considerado na violência contra o idoso. Algumas universidades, em parceria com organizações não governamentais, como ocorre no Texas ${ }^{(28)}$, criaram grupos de estudo para treinamento adequado de profissionais da saúde para lidarem com essa situação.

Ahmad e Lachs, em seus recentes estudos ${ }^{(29)}$, fazem referência à auto-negligência, como a Síndrome de Diógenes, reconhecida, assim, por conta da história do filósofo grego que rejeitou bens e conforto, vivia sujo e desalinhado, tendo morado num barril. Para definição da síndrome as características consideradas incluem esqualidez doméstica, retirada social, tendência a acumular lixo, falta de vergonha e recusa para ajuda (médica inclusive). Os idosos com essa síndrome normalmente vivem sós. Embora a auto-negligência seja, fundamentalmente, distinta de abuso contra o idoso, os clínicos deveriam ser atentos à síndrome, para que pudessem ocorrer as denúncias e, posteriormente, possível acompanhamento e tratamento desse tipo de violência. 
Ao considerar esses dados que trazem informações de existência de violência, seria possível pensar numa maior aceitação dos idosos em relação às perdas advindas do envelhecimento.

Porém, tal fato não é o observado: Minayo ${ }^{(30)}$ refere em seu estudo a atualidade da pesquisa realizada pelo antropólogo Simmons (1945), que avaliou a expectativa de idosos em 71 sociedades indígenas, em relação ao lugar que ocupavam em suas tribos. A autora relata não haver replicação de tal estudo, mas a relevância científica permite a citação após 60 anos, onde os resultados expressam, por parte desses idosos, o desejo de viver o máximo possível, encerrando a vida de forma digna e sem sofrimento, encontrando proteção à diminuição de sua autonomia física, participando das decisões comunitárias e prolongando as conquistas e prerrogativas sociais, como autoridade e respeito.

Em seu trabalho sobre violência e envelhecimento, Herrera( ${ }^{(31)}$ cita a relação de invisibilidade estabelecida com o idoso, onde seus familiares desconhecem o seu ser, ter e sentir, faltando com o reconhecimento social, político e finalmente, pessoal, desrespeitando sua individualidade, capacidade de decisão, participação e exigência de seus direitos.

Segundo pesquisa realizada pela OMS e o International Network for the Prevention of Elder Abuse (INPEA) ${ }^{(32)}$, sobre a violência aos idosos no Brasil, algumas das queixas levantadas pelos idosos, em relação a envelhecer é o sentimento de fossilização, sendo excluídos da participação social, sentindo-se infantilizados pelos seus familiares e inutilizados pela aposentadoria, com diminuição de seu padrão de vida devido à baixa renda, desrespeitados em seus direitos, que são estabelecidos apenas por serem "velhos", não por trabalharem toda uma vida e terem conquistado o direito do envelhecimento com respeito.

O editorial da revista The Lancet $^{(33)}$ discute a importância do tema, com a seguinte pergunta: "Como você gostaria de ser tratado quando tiver 75?" para apresentar a pesquisa de Lachs e Pillemer, que mostram o maior risco de o idoso submetido a violência morrer num período de três anos, em relação aos idosos que não sofreram tal situação. Discutem ainda, a importância do tema, que começou a ser pesquisado após 30 
anos de estudos da violência infantil, mostrando o quanto há o que estudar nessa área.

Wolf ${ }^{(34)}$ apresenta em suas pesquisas uma revisão de estudos sobre a violência contra o idoso, demonstrando que há uma década, na época em 1997, os Estados Unidos ainda buscavam uma forma de prevenir, identificar e cuidar da violência contra o idoso, situação que ainda é vista nas pesquisas atuais.

A autora apresenta os resultados de alguns estudos realizados na área de Boston, onde 32 de cada 1.000 pessoas de 65 anos ou e mais foram abusados fisicamente, verbalmente ou sofreram negligência. Num estudo nacional no Canadá em cada 1.000 idosos, 40 sofreram algum tipo de violência física ou verbal e 25 por 1.000 foram vítimas de exploração financeira. No Reino Unido, o procedimento utilizado incluía várias perguntas sobre abuso aplicadas a 2.000 adultos nos ônibus: pessoas com 60 anos e mais foram questionadas se um familiar ou parente os tinham assustado recentemente gritando, insultando ou falando asperamente (abuso verbal); se os tinham empurrado, esbofeteado, ou sido de qualquer forma fisicamente agressivos com eles (abuso físico) ou levado dinheiro ou propriedade deles sem consentimento (abuso financeiro). A pesquisa apresentou uma taxa de 53,9 por 1.000 idosos para abuso verbal e 15,2 por 1.000 idosos tanto para abuso físico como para abuso financeiro( ${ }^{(34)}$.

Um outro aspecto da violência contra idosos é ressaltado nas pesquisas de Phillips ${ }^{(35)}$, que atenta para a questão da violência contra as mulheres, em especial as que envelhecem e já sofriam violência doméstica e as que são idosas, mas cuidam de cônjuges ou familiares mais idosos e são agredidas por estes. Com esse estudo, a autora tenta demonstrar a importância desse cuidado, a vulnerabilidade da mulher em todas as faixas etárias, sua suscetibilidade para a violência e, principalmente, a complexidade do tema em questão de onde inicia a violência contra o idoso.

A questão da violência contra a mulher desde a idade jovem pode ser um dos motivos pelos quais as idosas têm maiores riscos de serem agredidas. Há o fato de as mulheres viverem mais anos sim, porém, 
pesquisadores do mundo inteiro questionam sobre o fato de a mulher já ser agredida quando jovem e, então, manter essa dinâmica no envelhecimento. Tal situação preocupa quando se verifica a pesquisa de Schraiber et al ${ }^{(36)}$ que identifica $29 \%$ de 1.172 mulheres com idade entre 15 e 49 anos, em São Paulo, que sofreram violência física e sexual em seus lares, isto é, se uma em cada dez mulheres foi vítima de violência sexual pelo seu próprio parceiro, ratificam-se as hipóteses sobre o padrão de alta violência contra a mulher mesmo antes de envelhecer e que se mantém, cronicamente, no envelhecimento.

Keikeiame e Ferreira ${ }^{(37)}$ também mostram, em seus estudos, que na África, as mulheres idosas de comunidades negras, em distritos municipais são subgrupo de alto risco para violência interpessoal e abuso. Tal condição é ressaltada quando, em suas pesquisas, incluem nas definições de abuso da OMS a questão da bruxaria, pois essas mulheres são condenadas a marcas de queimaduras na pele para serem identificadas como bruxas. Referem, ainda, a necessidade de aumentar o poder pessoal e político dessas mulheres e sua capacidade para autoproteção individual e coletiva.

Minayo ${ }^{(16)}$ relata que pesquisas em diversas culturas de diferentes países demonstram que pessoas de todos os status sócio-econômicos, etnias e religiões são vulneráveis à violência.

Em suas pesquisas sobre violência Mello Jorge $^{(38)}$ ressalta a importância de estudos nessa área, pois tal situação onera o sistema de saúde com suas conseqüências, elevando os níveis de mortalidade, reduzindo anos de vida produtiva, trazendo gastos com cuidados hospitalares e podendo, ainda, ocasionar seqüelas irreversíveis para a população.

É necessário, ainda, atentar para novas pesquisas que estão sendo desenvolvidas, como o estudo das seqüelas que esses idosos vítimas de violência apresentam no decorrer dos anos subseqüentes, como Mello Jorge sugere. Wolf ${ }^{(39)}$ refere um índice elevado de quadros depressivos como conseqüência de situações de violência, assim como estresse póstraumático, com quadros de excessivo medo, vergonha e alienação. Tais 
alterações nos idosos podem, inclusive, servir de diagnóstico para violência sofrida.

A questão da violência envolve não só o idoso vitimizado, mas sua família, os profissionais que cuidam dele e, numa perspectiva um pouco mais distante, o sistema de Saúde Pública, que tratará desse idoso e dessas seqüelas.

Outra questão interessante é a definição do termo a ser utilizado ao tratar da violência contra o idoso, que é uma tarefa de inúmeras pesquisas, sendo que, atualmente, a definição desse termo é cada vez mais discutida. Bernal e Gutièrrez ${ }^{(40)}$, em conjunto com seus colegas, no estudo que resultou no Guia de Atuação Contra os Maus Tratos aos Idosos, discutem criteriosamente essa dificuldade, demonstrando o quanto alguns termos como abuso ou mau trato, no singular, limitam a abrangência do tema nos estudos e no diagnóstico pelos profissionais de saúde e sugerem, assim como na Declaração de Toronto(41), o uso do termo maus tratos, por representar toda uma ação, com seus diferentes tipos e categorias a serem identificadas.

Tão importante quanto a definição do termo, é a dificuldade em estudá-lo nos moldes propostos pela saúde: nos estudos epidemiológicos a questão da violência está incluída em causas externas ${ }^{(42)}$, porém, essas duas expressões não se equivalem segundo Minayo ${ }^{(16)}$, que define as causas externas como uma categoria estabelecida pela OMS para referência às conseqüências das agressões, dos acidentes, dos traumas e das lesões. Violência, por sua vez, é uma noção referente aos processos e às relações sociais interpessoais, de grupos, de classes, de gênero, ou objetivadas em instituições, quando empregam diferentes formas, métodos e meios de aniquilamento de outrem, ou de sua coação direta ou indireta, causando-lhes danos físicos, mentais e morais. Para a autora, ainda, o termo "mau trato" é sinônimo de "abuso".

O Ministério da Saúde ${ }^{(43)}$ define maus tratos contra idosos como ações únicas ou repetidas que causam sofrimento ou angústia, ou ainda, a ausência de ações que são devidas, que ocorrem numa relação em que haja expectativa de confiança, conforme proposto em Action of Elder Abuse, 1995 e INPEA, 1998. 
A definição do termo a ser estudado leva a importante discussão, situação que foi vivenciada por outros grupos de pesquisas no assunto como Tatara et $a^{(27)}$ que relatam ter enfrentado impedimento inicial para uniformizar o termo abuso ao idoso, sendo necessário um processo de seleção, discussão e estudo do termo, uma vez que a maioria das definições utilizadas não permitem comparação entre si.

Segundo relato do pesquisador, várias etapas foram cumpridas, desde a análise das leis estatais para verificação dos termos mais comuns utilizados, discussão em mesas-redondas de profissionais na área, discussão com a comunidade, encontros para avaliação por peritos mais experientes e, ao final, a definição de termos a serem utilizados, aqui descritos:

- Abuso Físico: uso de força física que pode resultar completamente em dano, dor ou prejuízo físico.

- Abuso Sexual: contato sexual não-consensual de qualquer pessoa com um idoso.

- Abuso Emocional ou Psicológico: definido como o inflição de angústia ou dor emocional.

- Exploração Financeira ou Material: uso ilegal ou impróprio dos bens/ativos de idosos.

- Abandono: deserção do idoso por um indivíduo que teve custódia física ou caso contrário tinha assumido responsabilidade por prover cuidado pelo mesmo.

- Negligência: recusa ou fracasso para cumprir obrigações ou deveres para um idoso.

- Auto-negligência: foi caracterizado como os comportamentos de um idoso que ameace sua própria saúde ou segurança. A definição de auto-negligência exclui uma situação na qual uma pessoa mais velha mentalmente competente (que entende as conseqüências de suas decisões) toma uma decisão consciente e voluntária de se ocupar de atos que ameaçam sua saúde ou segurança.

A $\mathrm{OMS}^{(5)}$ define violência contra o idoso como um ato de acometimento ou omissão, que pode ser tanto intencional como involuntário. O abuso pode ser de natureza física ou psicológica ou pode 
envolver maus tratos de ordem financeira ou material. Qualquer que seja o tipo de abuso, certamente resultará em sofrimento desnecessário, lesão ou dor, perda ou violação dos direitos humanos e uma redução na qualidade de vida para o idoso.

Essa definição também foi detalhada pela instituição Action on Elder Abuse, no Reino Unido e adotada pela INPEA, que divide o abuso nas seguintes categorias ${ }^{(5)}$ : físico, psicológico ou emocional, financeiro ou material, sexual e negligência.

Em 1992, um seminário sobre abuso de idosos, realizado na África do Sul, estabeleceu diferença entre maus tratos e abuso, com intuito de tentar classificar a violência contra idosos num país emergente, com base num modelo ocidental, mas considerando fatores relevantes da população nativa. Desta forma, manteve a classificação como as citadas anteriormente, mas incluiu ${ }^{(5)}$ :

- Acusações de bruxaria: estigma e ostracismo.

- Abuso proveniente dos sistemas: o tratamento desumano a que todos os idosos estão sujeitos nas clínicas de saúde e repartições encarregadas das pensões e marginalização pelo governo.

Harbison e Morrow $^{(44)}$ referem a dificuldade de progresso nas pesquisas por conta do desacordo nas definições dos termos abuso contra idoso, negligência e seus parâmetros de caracterização, o que prejudica os estudos de incidência e prevalência, mas não desvaloriza a importância do tema, já que as experiências negativas nesse tema intensificam a necessidade de maiores estudos.

Zolotow $^{(45)}$ chama a atenção para violência implícita, pois acomete os idosos de maneira velada, quando os mesmos são supostamente preservados de situações que teriam condições cognitivas e emocionais para lidar. Alguns pesquisadores relacionam tal fato à infantilização do idoso, que acaba por privá-lo de um direito de participação e decisão da vida que possui.

Ainda em estudos de Hudson ${ }^{(11)}$ verificam-se diferentes autores que tentam separar o abuso de negligência, pois acreditam que nessas 
situações fala-se de agressores e riscos diferenciados e, portanto, passíveis de tratamentos distintos.

Desta forma, entre diferentes definições, dois termos são muito encontrados nos atuais artigos e referências ao tema: "violência" e "maus tratos". Na concepção deste estudo, violência parece englobar o termo maus tratos no âmbito de estudos epidemiológicos.

Muitos autores referem a questão da violência como a ponta de um iceberg a ser estudado, pois envolve o tipo de violência perpetrada, fatores de riscos para vulnerabilidade, quem é o agressor e o perfil desse agressor.

Minayo $^{(16)}$ relaciona esse iceberg à cultura relacional de dominação, de conflitos intergeracionais e às negligências familiares e institucionais.

Independentemente da definição de violência, alguns trabalhos estudam os riscos para o idoso ser considerado vulnerável, como no Mapa de violência, divulgado pela $\mathrm{OMS}^{(46)}$, onde algumas características são identificadas como fator de risco: relações familiares desgastadas, idoso dependente, dificuldades financeiras, isolamento social, fatores culturais e sócio-econômicos, distribuição de heranças e migração dos jovens (deixando idosos solitários).

Wolf ${ }^{(34)}$ mostra, em suas pesquisas, a dificuldade em estabelecer esses fatores de risco para identificação do agressor e do idoso vulnerável à violência, mas refere que em duas décadas de estudo, entre resultados ainda insuficientes, as tendências apontam para a dependência do agressor pela vítima, especialmente para apoio financeiro; o estado psicológico do agressor (por exemplo: abuso de drogas/álcool, história de doença mental); a situação física da vítima e seu estado cognitivo; o isolamento social e familiar. Relata ainda pequena evidência empírica entre eventos de vida estressantes e história de violência, como vitimização infantil e violência conjugal, como possíveis desencadeadores do abuso contra o idoso.

Nesse mesmo raciocínio existe o trabalho de Azevedo, do Laboratório da Criança, LACRI/USP(47), onde se desenvolve todo o acompanhamento da situação de violência no local do acontecimento da mesma que, no caso da criança, muitas vezes se dá dentro de seu próprio lar, 
coincidentemente com as histórias de violência contra o idoso também. $O$ LACRI acredita que o agressor precisa do tratamento psicológico e orientação social para que não reincida na situação de agressão e, por sua vez, que essa criança seja acompanhada para que, além de evitar traumas da agressão vivenciada, ela não seja no futuro, um possível perpetrador desse agressor que irá envelhecer.

Ou seja, refere-se a ciclo de desenvolvimento da violência dentro do núcleo familiar: a criança vitimizada hoje por um parente próximo, pode no futuro ser a agressora desse parente que se tornará um idoso, como se verifica em alguns grupos atuais de pesquisa $\left(\operatorname{Ramos}^{48}\right)$.

Souza et $a^{(49)}$ desenvolveram pesquisa no Município de Juquié, BA, para estabelecer fatores de risco de violência contra o idoso na sua relação com cuidador e encontraram, como resultados para risco do idoso: idade predominante de 80 anos $(30 \%)$, maioria de mulheres $(72 \%)$, viúvas $(48 \%)$, com quadro de comorbidade associando alterações geriátricas e patologias, $80 \%$ desses idosos se diziam em desarmonia familiar, tinham algum membro alcoolista na família (34\%), dependiam de outra pessoa (32\%), 70\% sentiam-se atrapalhando a vida do cuidador e apenas $5 \%$ referiram sofrer violência. Para o risco do cuidador: idade acima de 60 anos (26\%), cuidadoras (82\%), com distúrbios osteomusculares (46\%) e depressão (38\%), sendo que eram cuidadoras em tempo integral $(80 \%), 34 \%$ diziam cuidar do idoso por obrigação moral e apenas $12 \%$ referiam problema familiar, o que a autora observa como contraponto à percepção do idoso, demonstrando a ambigüidade na percepção de risco para ocorrência da violência.

O INPEA ${ }^{(50)}$ apresentou um quadro representativo sobre os riscos para os idosos sofrerem algum tipo de abuso e sugere a divulgação mundial do mesmo pois, dessa forma, pode-se pensar numa suposta padronização desses riscos, que serviria de orientação nas unidades de atendimento de saúde aos idosos.

Nos mesmos moldes, mas de maneira mais sucinta, Alonso ${ }^{(51)}$ também sugere, em seu grupo de estudo, um quadro semelhante: 
Quadro 1: Indicativos de risco para violência doméstica contra o idoso

\begin{tabular}{|l|l|}
\hline \multicolumn{1}{|c|}{ Risco para o idoso } & \multicolumn{1}{|c|}{ Risco para o agressor/cuidador } \\
\hline Idade elevada & Sobrecarga física \\
Deficiência no estado de saúde & Sobrecarga emocional \\
Incontinência & Sofrer de transtornos \\
Deterioração cognitiva & psicopatológicos \\
Mudanças comportamentais & Abuso de álcool \\
Dependência física & Vícios \\
Dependência psíquica & Antecedente de violência familiar \\
Isolamento social & prévia \\
Antecedente de maus tratos & Incapacidade emocional do cuidador \\
\multicolumn{2}{|c|}{ Situações especiais de vulnerabilidade para risco } \\
\hline Viver na mesma residência \\
Dinâmica desgastada entre a vítima e o agressor \\
Falta de apoio familiar, social e financeiro \\
Dependência econômica do idoso \\
\hline
\end{tabular}

O objetivo da autora é incentivar a identificação desses casos de violência, uma vez que, em seu país de pesquisa, Espanha, as evidências epidemiológicas para a situação também são sub-notificadas.

Guedes $^{(52)}$ relata o trabalho da antropóloga Guita Debert que refere que, nos casos em que estudou a violência contra idosos, a maioria das agressões foram perpetradas pelos próprios filhos ou parentes próximos.

Assim, tão importante quanto a padronização de fatores de risco é a identificação dos agressores.

Segundo dados do Instituto Brasileiro de Investigações Criminais (IBICRIM), na análise de 1.500 processos envolvendo idosos, $40 \%$ das queixas são contra os filhos, netos e cônjuges e $7 \%$ contra familiares por questões de abuso financeiro(53).

Em Bogotá, as denúncias relatadas por Herrera ${ }^{(31)}$ mostram, no ano de 1996, 177 lesões não fatais por familiares dos idosos, sendo $47 \%$ geradas pelos filhos. 
No Canadá(54), em 1991, foram investidos 136 milhões de dólares canadenses na parceria com a população para eliminar a violência familiar e abuso ao idoso, demonstrando a gravidade do problema identificado no ambiente doméstico destes idosos.

Alguns estudos sugerem um padrão de identificação do agressor familiar: por ordem de freqüência, são identificados como agressores primeiramente os filhos, seguidos das filhas, noras, genros e esposos ${ }^{(30)}$.

Menezes ${ }^{(5)}$ relata o quanto depender de outra pessoa significa estar em poder dela e refere que a condição de dependência cria uma relação íntima de reciprocidade com a agressão. Relata, ainda, que para alguns estudiosos o ser humano tem como característica negativa uma tendência para maltratar seres mais indefesos.

Acreditando nessa teoria, alguns estudiosos a relacionam com o risco para as mulheres idosas serem vítimas de violência, como Plouffe ${ }^{(56)}$, em estudo canadense, que cita os riscos de as mulheres idosas, se comparadas aos homens, terem maior probabilidade de envelhecer em situação de pobreza, de viverem sozinhas e de dependerem de assistência médica crônica e de serviços sociais sem recursos adequados, caracterizando, assim, diversos quadros de violência contra o idoso.

Outra possibilidade de intensificar o risco para sofrer violência é representada pelas situações de maior dependência ou perda de cônjuge, pois devido à mudança na estrutura familiar vivenciada hoje pela sociedade, muitas vezes, o espaço físico das residências não comporta mais esse idoso, que acaba restrito a um quarto na residência. Em outras situações, se o idoso é dependente fisicamente de cuidados, não há quem possa cuidá-lo, já que, atualmente, todos os filhos estudam ou trabalham e as esposas (filhas ou noras), antes cuidadoras, agora também são atuantes no mercado profissional| ${ }^{(57,58)}$.

Com isto, a linha entre dificuldade de viabilização de cuidados ao idoso e violência, torna-se frágil e tênue, principalmente se for considerado o abuso psicológico, mostrando a necessidade de maiores estudos para delimitação mais estruturada e clara de tal condição, opinião reforçada por Herrera ${ }^{(31)}$ em suas pesquisas. 
Outra questão que tem se tornado cada vez mais pertinente de atenção é o abuso financeiro que, antigamente, era visto nas famílias de muitas posses, mas hoje, infelizmente, atinge cada vez mais camada menos privilegiada da população e traz conseqüências desastrosas para os idosos. É cada vez mais comum o surgimento de pessoas que pretendem auxiliar o idoso nas questões previdenciárias e lhes tomam o pouco dinheiro de que dispõem ${ }^{(58,59)}$ ou as situações de empréstimos com descontos em folha de recebimento de aposentadoria que, em alguns casos, não condizem com o contratado.

Para o idoso, além da violência financeira, deve-se pensar na questão psicológica que envolve tal situação, já que o mesmo, diante de tal fato, muitas vezes, abate-se com a impotência da situação e cria-se uma avalanche de perdas: financeiras, psíquicas e até de saúde física, muitas vezes, irreversíveis.

No âmbito institucional, é reconhecido o estudo de Guerra et al ${ }^{(60)}$, sobre a mortalidade de idosos na Clínica Santa Genoveva no Rio de Janeiro, onde é questionada a vulnerabilidade a que este grupo etário está exposto. Hoje, uma década após o ocorrido na Clínica, houve a condenação em primeira instância dos responsáveis pela situação lá encontrada em 1996 ${ }^{(61)}$. A discussão do Estatuto do Idoso e seu vigor colaboraram para que casos como esse tenham maior vulto na sociedade.

Situações que envolvam a questão institucional sugerem maior facilidade de identificação, pois não conduzem diretamente à questão emocional do agressor dentro da própria casa do idoso; porém, pesquisas recentes mostram dados alarmantes, embora ainda insuficientes, dessa realidade implícita na população.

Numa tentativa de coletar maiores informações na população brasileira, devido a esse déficit de informações, Gaioli(62) desenvolveu trabalho em Ribeirão Preto, no qual encontrou maior incidência de maus tratos no domicílio em idosos do sexo masculino (58,6\%), com idade média em 75 anos. A maioria era casada $(45,2 \%)$ e sofreu agressões por familiares como genros, noras, filhos e netos $(47,1 \%)$; a grande maioria não buscou auxílio médico $(57,4 \%)$. 
Gawryszewski et al ${ }^{(63)}$ realizaram estudo sobre mortes e internações por causas externas nos idosos, concluindo que as causas da mortalidade da população idosa diferem da população em geral, predominando o componente não intencional, sendo elevadas as taxas de mortalidade por acidentes de trânsito e, em outro extremo, as taxas de homicídio reduzidas; configurando assim, a especificidade dos riscos em idosos, o que demonstra as características individuais desse grupo, sendo mais indicados estudos individualizados e específicos. Também é referida a preocupação entre as autoridades de saúde pública em especificar dados de violência contra idosos no Brasil.

Barbosa $^{(64)}$ relaciona $\circ$ entendimento da violência pelos profissionais de saúde com a questão de identificação das causas externas, referindo que esse profissional só dimensiona a importância da violência ao deparar com a situação da mortalidade. Porém, no trato diário, há dificuldade em reconhecer os sinais de possível violência, que possibilitariam a intervenção para prevenção, antes de um caso real estabelecido.

Segundo o Sistema de Informações Hospitalares (SIH), em 2000, no Brasil, existiram 92.796 internações por causas externas de idosos por violências e acidentes, sendo que $52,1 \%$ correspondiam a quedas sofridas por esses idosos numa relação de três quedas não fatais para uma fatal ${ }^{(16)}$. Entre essas três quedas não fatais podem ter ocorrido casos de perda de autonomia, maior dependência física. Considerando que os idosos são um grupo mais vulnerável, sobretudo nos casos de múltiplas dependências e incapacidades, é possível um aumento, no caso de violência em decorrência das quedas, por uma outra violência, como negligência. Ou seja, há um ciclo que se auto-alimenta.

As quedas são associadas à osteoporose, instabilidade visual e postural, e negligências ${ }^{(16)}$.

Sethi et al ${ }^{(65)}$ apresentam, em seus estudos na Europa, em média 72.000 idosos com 80 anos e mais que morrem anualmente por quedas. Sugerem e ressaltam a importância de intervenções como avaliação de risco nas residências, com modificação do espaço doméstico e público; desenvolvimento de produtos que assegurem a segurança para prevenir 
quedas; treinamento de pessoas para orientação desses idosos; desenvolvimento de atividades físicas com os idosos para manutenção do equilíbrio físico-motor. Os autores acreditam que essas intervenções possibilitariam uma redução de $51 \%$ no número de mortes por quedas em idosos.

O Ministério da Saúde ${ }^{(42)}$ cita a falta de dados estatísticos sobre incidência e prevalência de violência contra o idoso em pesquisa no Brasil, mas chama a atenção para a vulnerabilidade do idoso, demonstrando que as quedas pela instabilidade visual e postural, representam os principais acidentes entre os idosos, sendo que $1 / 3$ dos idosos que residem em casa e metade dos que vivem em instituições sofrem ao menos uma queda ao ano, com fratura de colo de fêmur, seguida de hospitalização. Metade desses idosos falece dentro do prazo de um ano e a outra metade fica dependente de cuidados de terceiros, com perda de autonomia física.

Ainda a mesma publicação atenta para outros acidentes sofridos pelos idosos, como queimaduras, intoxicações, atropelamentos, sufocações e outras lesões relacionadas à fragilidade da idade em relação aos riscos presentes em ambiente doméstico e público; porém, tais situações são incorretamente diagnosticadas devido a um conjunto de fatores: a falta de informação e despreparo dos profissionais de saúde, descaso dos familiares, receio dos idosos em citar alguém de sua própria família.

Recentemente, foi publicado 0 artigo de Lachs et $\mathrm{al}^{(66)}$, onde foi sugerido um protocolo de identificação de violência, por profissionais da saúde, utilizando como critério alguns dos fatores propostos pela OMS: abuso financeiro, idoso portador de demência, estresse de cuidadores, isolamento social, cuidador portador de doença mental ou alcoolista, relações de dependência financeira e coresidência com o agressor.

A idéia de desenvolvimento de protocolo para atendimento desses casos leva alguns pesquisadores, como Reis ${ }^{(67,68)}$, a estudar escalas de rastreio para identificação rápida de indicadores de abuso, a fim de que equipes de saúde possam ter acesso a possíveis casos de maus tratos de maneira rápida e eficaz. Reis propõe o uso da Indicators of Abuse Screen (IOA), onde o entrevistador possui um "check list" de situações e 
comportamentos de risco para maus tratos, avaliando o idoso e seu cuidador, de maneira não invasiva, que muitas vezes, dificulta 0 diagnóstico de tal situação.

Ahmad e Lachs ${ }^{(29)}$ falam em seus estudos da importância de o profissional da saúde ter consciência da necessidade da notificação desses casos, pois embora as leis variem de país para país, a omissão é crime, porém poucos são punidos legalmente. Os autores sugerem a existência de um protocolo na área de saúde, comum a todos, como atualmente é feito nos casos de rastreio de quadros demenciais, onde naturalmente todos os profissionais já utilizariam esse protocolo diante da necessidade de uma investigação de possível situação de violência. Nas próprias unidades de atendimentos as equipes dariam o encaminhamento correto numa situação dessas ${ }^{(69)}$.

Relatam, ainda, a necessidade de um assistente social na equipe para conduzir a situação e dar os encaminhamentos legais, avaliando os recursos desse idoso e de sua família; enfermeira para cuidados básicos; médico para tratamentos necessários, psiquiatra ou psicólogo para condução das questões psíquicas. Sugerem, ainda, um representante legal e um administrador pessoal, que saberiam conduzir a equipe para que não houvesse julgamento da situação, mas, sim, acolhimento no momento desse diagnóstico. Acreditam que, se o idoso sofreu violência por terceiros, o caso será conduzido de maneira mais rápida, porém, se o idoso sofreu violência doméstica, os processos de identificação na equipe podem prejudicar o encaminhamento do caso. Os autores acreditam que, nesse caso, é necessário tratar a família e não só seu idoso.

Em 2002, a OMS iniciou um levantamento em dez países para ouvir grupos de idosos e investigar a situação em que vivem, entre elas a situação da violência. O Brasil participa dessa pesquisa, onde relatos sobre abuso físico e verbal começaram a ser identificados ${ }^{(70)}$.

Neste mesmo ano, a OMS publicou uma declaração canadense para prevenção de maus tratos e abusos contra idosos, onde esclarecia os tópicos a serem considerados nos estudos, enfatizando a falta, com freqüência, de marcos legais de identificação de maus tratos. Refere, ainda, a necessidade da participação de múltiplos setores da sociedade 
em campanhas de prevenção, paralelamente ao desenvolvimento e treinamento dos profissionais de atenção primária da saúde; a educação e informação através de setores formais (escolas, universidades), mas também pelos meios de comunicação e, principalmente, a necessidade da conscientização de que violência contra o idoso é um fato mundial, que acomete tanto os países em desenvolvimento quanto os países desenvolvidos e, portanto, deveria ser passível de uma investigação de prevalência mundial, assim como campanhas de orientação e prevenção.

Independente dos locais de realização dos estudos sobre a violência contra o idoso, quase sempre há indícios do envolvimento familiar na situação. Considerando que a população que está envelhecendo terá parcela dependente por doenças crônicas e degenerativas, demandando, portanto, maior relacionamento com esses familiares para cuidados e, possivelmente, a necessidade de um cuidador domiciliar, - tendência atual ${ }^{(71,72)}$ - esses vínculos devem ser repensados, com intuito de maior prevenção da situação de violência vivenciada pelo idoso.

Desta forma, considerando a realidade brasileira, um dos pontos de partida para uma possível campanha de orientação e prevenção poderia contar com o apoio dos agentes do Programa Saúde da Família, implantado considerando bases propostas pela Política Nacional da Saúde do Idoso(73), para esse trabalho. Devido à necessidade de suas próprias atribuições, os agentes têm acesso e contato com esses idosos, dentro de seu ambiente familiar, o que possibilitaria o desenvolvimento da conscientização para evitar a violência contra o idoso ou, no caso de existir, o tratamento e acompanhamento da situação.

A atual realidade mundial sobre o assunto é de tamanha importância que a International Network for the Prevention of Elder Abuse (INPEA) $^{(49)}$ escolheu o dia 15 de junho de 2006 como o Dia da Consciência Mundial na luta contra a violência aos idosos.

Para isto, sugeriu uma série de etapas a serem desenvolvidas com o intuito de criar, nas comunidades, a consciência da gravidade do assunto, para que não seja apenas um dia de luta, mas sim, a transformação cultural dessas sociedades. 
Atualmente, verifica-se uma maior atuação dos idosos na população, em decorrência do desenvolvimento tecnológico e científico, maiores possibilidades médicas de melhorias nas condições de saúde, estimulação de informações pela mídia. Assim, o idoso permanece atuante na sua comunidade durante mais tempo, o que lhe traz possibilidade de gratificação, quando bem aceito, ou decepção e possível depressão, se frustradas as suas expectativas.

Antigamente, era visto quase em todas as sociedades que o idoso transmitia o conhecimento ao mais jovem mas, hoje, com o desenvolvimento tecnológico e a globalização das informações, os mais jovens têm acesso a informações que nem sempre são atingidas pelos idosos e já não identifica-se mais quem ensina e quem aprende ${ }^{(12)}$.

Portanto, essa consciência mundial sobre a violência pode modificar uma estrutura que está se formando de maneira frágil e, se o envelhecimento mundial mantiver esse padrão atual; em breve, a situação de violência será muito semelhante à vivida pelas mulheres e crianças. Mas, se os jovens forem conscientes da possível relação de troca que existe com o idoso, e não mais vê-lo como parte a ser desprezada na sociedade, talvez, seja o princípio de uma campanha de conscientização e prevenção mundial.

Minayo ${ }^{(30)}$, em seu estudo sobre violência contra idosos, realizou revisão bibliográfica de literatura nacional e internacional para estudo da mortalidade e morbidade de idosos brasileiros por "causas externas", e em suas observações cita que países como Estados Unidos e Canadá, revelam uma prevalência de violência de $10 \%$ para toda população idosa, dado que não pode ser comprovado no Brasil devido à deficiência de informações neste aspecto, segundo a autora.

Em 1995, Veras ${ }^{(74)}$ apontava para a necessidade de produção científica sobre a população idosa brasileira, devido ao padrão de crescimento populacional verificado na época.

A maioria dos estudos sugere a necessidade de pesquisas mais específicas, sempre relacionando a questão com as políticas de Saúde Pública e o desenvolvimento da equipe interdisciplinar para identificação de sinais de violência em idosos, assim como o estudo da cultura de cada 
local, para definição clara e objetiva desse limiar tênue entre a violência e as relações estabelecidas com o idoso ${ }^{(23,30-32,34,62,65,75,76) \text {. }}$

Menezes ${ }^{(55)}$ refere a violência como uma epidemia, sendo que seu aumento provocou efeitos nas saúdes física e mental da população e está se convertendo em um problema de Saúde Pública, pois quando a violência debilita a saúde, atinge também o potencial de desenvolvimento humano de um país. A violência contra os idosos será o fim das histórias passadas e a prospecção de um triste futuro para o envelhecimento mundial.

Considerando essa discussão e avaliando que, em 1996, a Assembléia de Saúde Mundial declarou violência um assunto de saúde pública ${ }^{(77)}$, declaração que foi reforçada pela publicação do Relatório Mundial em Violência e Saúde, pela Organização Mundial de Saúde, em 2002 $2^{(5)}$, avalia-se a importância desse estudo na área de Saúde Pública.

A Saúde Pública poderá contribuir com enfoque na prevenção, desenvolvimento científico, com seu elevado potencial para administrar equipes multiprofissionais e transitar inter-setorialidade das políticas públicas e, além de tudo, assegurar atendimento e orientação a essas vítimas da violência ${ }^{(77)}$.

Assim, o objetivo deste estudo é verificar os possíveis sinais de violência observados pelas entrevistadoras do Estudo SABE - Saúde, Bem Estar e Envelhecimento, estudo multicêntrico com pessoas de 60 anos e mais na América Latina e Caribe, realizado em São Paulo, composto pelos idosos residentes no ano de 2000, na área urbana do município ${ }^{(78)}$. 
2.1. Objetivo Geral:

Estudar os idosos com suposta condição de violência, entrevistados no Estudo SABE.

2.2. Objetivos Específicos:

2.2.1. Caracterizar os idosos com suposta condição de violência segundo variáveis relacionadas a idade, escolaridade, sexo, estado marital, condição cognitiva, estado de saúde, estado funcional, condição nutricional e situação financeira.

2.2.2. Comparar os resultados encontrados com aqueles dos idosos sem indicativo de violência, a fim de estabelecer possíveis determinantes para violência. 
METODOLOGIA 


\subsection{O Estudo SABE}

No período de 1997 a 2003 a Organização Pan Americana de Saúde (OPAS) coordenou um estudo multicêntrico denominado SABE Saúde, Bem-Estar e Envelhecimento - para traçar o perfil dos idosos na América Latina e no Caribe. Esse estudo foi planejado para colocar luz nas demandas de saúde que poderão emergir de uma população que se tornou rapidamente idosa e pela necessidade de antecipar o que se encontrará adiante, de modo que os países possam se planejar adequadamente para prevenir as conseqüências mais negativas do processo de envelhecimento na região ${ }^{(78)}$.

No estudo SABE foram incluídos: Argentina, Barbados, Brasil, Chile, Cuba, México e Uruguai. Esses países representavam uma combinação daqueles que trazem uma boa representação dos vários estágios do envelhecimento na região. Argentina, Barbados, Cuba e Uruguai estão em estágios muito avançados do processo de envelhecimento, enquanto Chile, México e Brasil estão ligeiramente atrás, mas a velocidade com que esse processo ocorre em tais países pode fazê-los, muito em breve, superar os primeiros.

Esse estudo, caracterizado por ser transversal, simultâneo, bastante abrangente e construído de forma a ser rigorosamente comparável foi o primeiro desse tipo na região. Teve por finalidade recolher uma ampla quantidade de informações cujos resultados pudessem subsidiar tanto o desenvolvimento de outros estudos complementares, quanto a organização das políticas públicas destinadas a esse grupo etário na região.

\subsubsection{Instrumento}

Os dados foram obtidos em entrevista domiciliar, por meio de um questionário elaborado por um comitê regional composto pelos principais pesquisadores de cada país e por especialistas em temas específicos da pesquisa. Inicialmente o instrumento foi submetido a dois pré-testes até chegar à forma final, subdividido em onze seções (ANEXO B)*:

\footnotetext{
* disponível em http://www.fsp.usp.br/sabe e anexo em forma eletrônica ao final deste estudo.
} 
Seção A - Dados pessoais

Ano e país de nascimento; local de residência durante os primeiros quinze anos de vida; local de residência durante os últimos cinco anos de vida e, onde fosse aplicável, razões para a mudança de residência; história e estado marital; número de filhos; sobrevivência dos pais e, se não, a idade em que faleceram; escolaridade.

\section{Seção B - Avaliação cognitiva}

Auto avaliação da memória; avaliação da memória pelo teste Mini Mental, modificado e validado no Chile para a realização do estudo. Para os que obtivessem escore igual ou inferior a 12 pontos, uma escala de desempenho funcional era administrada a um proxi-respondente (informante substituto) a partir da questão "é capaz de...".

\section{Seção C - Estado de saúde}

Auto avaliação da saúde atual e comparativa ao ano anterior, bem como da saúde na infância, doenças referidas, considerando nove das condições crônicas mais prevalentes na população idosa e incluindo seu tratamento; hábitos, condições sensoriais, saúde reprodutiva, saúde bucal; ocorrência de quedas; escala de avaliação de depressão geriátrica e mini-screening nutricional.

\section{Seção D - Estado Funcional}

Avaliação do desempenho funcional e da ajuda recebida, quando necessário, nas atividades básicas e instrumentais da vida diária e identificação e caracterização do(s) cuidadores principais.

\section{Seção E - Medicamentos}

Terapêutica medicamentosa utilizada, incluindo indicação, tempo de uso, forma de utilização, obtenção e pagamento; gastos mensais com medicamento e motivos referidos para a não utilização dos medicamentos prescritos. 
Seção F - Uso e acesso a serviços

Serviços de saúde utilizados, públicos ou privados, nos últimos 12 meses e ocorrência de hospitalização, atendimento ambiental, exames nos últimos quatro meses, bem como tempo de espera para atendimento, terapêutica prescrita e gastos relacionados.

Seção G- Rede de apoio familiar e social

Número e características de pessoas que vivem com o idoso no mesmo domicílio (sexo, parentesco, estado marital, idade, escolaridade e condição de trabalho); assistência prestada ao idoso e fornecida por ele referente a cada membro citado; tempo gasto na ajuda ao idoso. As mesmas perguntas foram feitas em relação aos irmãos e filhos que não vivem no mesmo domicílio, bem como a outros familiares e que, de alguma forma, fornecem ou recebem ajuda do/ao idoso; assistência recebida ou fornecida nos últimos 12 meses de alguma instituição ou organização; participação do idoso em algum serviço voluntário ou organização comunitária.

Seção $\mathrm{H}$ - História laboral e fontes de renda

Trabalho atual (tipo, renda, razões para continuar trabalhando); caso não trabalhasse mais, por quê não o fazia, ocupação que teve durante o maior período de sua vida, horas trabalhadas, razões para mudar de atividade, aposentadoria, pensões, benefícios, outras fontes de renda, renda total pessoal e número de dependentes dessa renda; gastos pessoais (moradia, transporte, alimentação, vestimenta, saúde ) e autoavaliação de seu bem estar econômico.

Seção J - Característica de moradia

Tipo e propriedade da moradia, condições de habitação (saneamento básico, luz, número de cômodos, bens presentes). 
Seção K - Antropometria

Altura do joelho, circunferência do braço, cintura, quadril, prega triciptal, peso, circunferência da panturrilha, largura do punho e força da mão.

Seção L - Flexibilidade e Mobilidade

Provas de equilíbrio, mobilidade e flexibilidade.

Sobre a violência doméstica: É importante o esclarecimento que o instrumento não possuía questões direcionadas à avaliação de violência diretamente, sendo essas anotações elaboradas pelas entrevistadoras ao final de todo o questionário com o preenchimento de observações sobre o tema. O SABE não tinha o objetivo de estudar especificamente o assunto, fato que será revisto na próxima edição do estudo, com inclusão de seção específica para dados de violência.

\subsubsection{Amostra}

Em todos os países, fizeram parte da amostra pessoas com $60 \mathrm{e}$ mais anos, com exceção do México, que ampliou sua amostra incluindo mulheres de 50 anos e mais.

Com exceção de Barbados, que utilizou o registro de eleitores, as amostras foram calculadas a partir do censo de cada país. Essas amostras foram probabilísticas e utilizaram o método de Amostragem por Conglomerados Polietápico, com estratificação das unidades primárias da amostra,com exceção do Chile, que não aplicou a estratificação. Em seis dos países, o processo de amostragem contou com três etapas (Barbados contou com duas, aplicando os critérios probabilísticos em cada uma delas). Cinco dos países consideram os estratos socioeconômico (com exceção de Chile e Cuba que fizeram isso posteriormente). México e Argentina também definiram estratos geográficos.

Em todos os países a distribuição da amostra foi realizada pelo método de Fixação Proporcional ao Tamanho. Inicialmente estavam previstas 1.800 entrevistas em cada país do estudo. No entanto, devido à 
disponibilidade ou a restrições no orçamento de cada local, essas metas foram ajustadas para mais ou menos da proposta original. A amostra final proposta foi de 13.023 idosos para todos os países participantes, sendo que se obtiveram 10.906 entrevistas, correspondendo a uma taxa média de resposta de $80 \%$, variando de $62,8 \%$ na Argentina, para 95,3\% em Cuba. Em São Paulo (Brasil), a taxa de resposta foi de 84,6\%. Esse total correspondeu a $92 \%$ da meta originalmente prevista, que é considerada satisfatória para estudos desse tipo, e resultou em 2.143 respondentes.

Em quatro dos sete países, sendo o Brasil um deles, foi aplicado algum tipo de procedimento para sobredimensionar a seleção de idosos em velhice avançada (com 75 anos e mais).

Os métodos de estimação e ponderação aplicados correspondiam à utilização de estimadores simples, não enviesados, e estimadores de Razão que consideraram, em todos os casos, o cálculo dos fatores de expansão do desenho amostral empregado, ou seja, as probabilidades de seleção aplicadas em cada etapa e as não-respostas. Foram também consideradas as variáveis sexo e grupos etários, dadas as diferenças de mortalidade entre sexo e o sobredimensionamento da população igual e superior a 75 anos. Ao final, se obteve um fator para cada indivíduo da amostra, que resumia todos os elementos mencionados no desenho amostral e os estratos considerados.

No Brasil, a população do estudo foi composta pelos idosos residentes, no ano de 2000, na área urbana do Município de São Paulo, cujo cálculo teve por base a contagem populacional da Fundação IBGE, de 1996. A amostra final foi composta pela somatória de uma amostra probabilística (sorteio) e de uma amostra intencional (composição livre para os grupos ampliados para complementar a amostra de idosos em velhice avançada). Para realização da amostra probabilística, foi utilizado o cadastro permanente de 72 setores censitários existente na Faculdade de Saúde Pública da Universidade de São Paulo, coordenadora do estudo no Município, selecionados sob o critério de probabilidade proporcional ao número de domicílio do cadastro da PNAD (Pesquisa Nacional por Amostra de Domicílios) de 1995. Em seguida, foram sorteados sistematicamente os domicílios a serem visitados. A complementação da 
amostra de pessoas de 75 anos e mais foi realizada pela localização de moradias próximas aos setores selecionados ou, no máximo, dentro dos limites dos distritos aos quais pertenciam os setores sorteados.

Para a análise dos resultados, foi atribuído a cada questionário um peso relativo à sua representatividade na população.

Dessa forma, a amostra final, por país, foi assim composta:

a) Argentina - 1.043 idosos

b) Barbados - 1.812 idosos

c) Brasil - 2.143 idosos( sendo 1.568 da amostra probabilística e 575 da amostra intencional)

d) Chile -1.306 idosos

e) Cuba - 1.905 idosos

f) México -1.247 idosos

g) Uruguai -1.450 idosos

Adicionalmente em quase todos os países, as unidades primárias de amostragem foram estratificadas e foram utilizados métodos não enviesados de estimação.Foram consideradas a estratificação da amostra, as probabilidades de seleção aplicadas em cada etapa da amostra e as técnicas de pós-estratificação por sexo e grupos etários, permitindo, assim, que os resultados obtidos nos países pudessem ser comparáveis entre si.

\subsubsection{Procedimentos de coleta de dados}

Após a seleção da amostra, os idosos foram entrevistados em seus domicílios. A maior parte das entrevistas $(88 \%)$ foi feita de forma direta. Nos restantes utilizou-se um proxi-respondente quando havia impossibilidade do idoso para responder às questões (problemas físicos ou cognitivos).

A coleta de dados ocorreu em duas etapas. Na primeira, foram preenchidas as seções de $\mathrm{A}$ a $\mathrm{J}$ e, na segunda, que ocorreu de um a seis meses após a primeira, as seções L e K. Isso ocorreu, em parte, pela extensão do questionário e, por outro lado, pelo fato de as seções $L$ e $K$ 
exigirem maior disponibilidade do idoso para a realização de alguns testes, além de material específico.

O estudo SABE foi submetido aos respectivos comitês de ética dos países envolvidos. No Brasil, o mesmo foi aprovado pelo Comitê de Ética da Faculdade de Saúde Pública da Universidade de São Paulo e pela Comissão Nacional de Ética em Pesquisa - CONEP, assim como este estudo (ANEXOA).

3.2. Metodologia utilizada no Estudo da Violência Doméstica contra Idosos

Para o desenvolvimento desta pesquisa foram utilizados dados obtidos no estudo SABE, considerando os comentários das entrevistadoras que, ao final de cada entrevista deveriam preencher uma seção destinada às suas observações, caracterizada como Perguntas e Comentários Finais. Nesta seção encontrava-se uma questão de observação direta de situação de violência, abandono ou maus tratos em relação aos idosos entrevistados, conforme descrito a seguir:

PCF 1. Observou situação de violência, abandono ou maus tratos de algum integrante da casa com relação ao entrevistado?

Essa pergunta serviu de base para a análise dos supostos casos de violência.

Havia a pergunta seguinte para descrição do tipo de situação observada:

PCF 2. Descreva a situação:

Através dessa questão poderiam ser identificadas as situações de violência que as entrevistadoras supostamente observaram. 
Em virtude das dificuldades em se constatar a violência contra os idosos, o estudo SABE não se propôs a incluir pergunta direta sobre o assunto no núcleo do questionário, limitando-se a pedir ao entrevistador que relatasse qualquer sinal de uma possível violência.

O desenvolvimento deste estudo se deu pela análise das duas questões acima apresentadas, em relação às variáveis coletadas das questões dos blocos temáticos do questionário do projeto SABE (Anexo B), consideradas importantes para a caracterização da população em estudo, conforme descrito abaixo:

\section{- Seção A - Informações Pessoais}

- Dados de idade (A1b), escolaridade (A5a e A6), estado marital (A13a).

- Embora a variável sexo (C18) esteja dentro da seção C (pois funciona como filtro) ela é uma variável de natureza pessoal e, assim, será incluída neste bloco.

\section{- Seção B - Avaliação Cognitiva}

- Dados de condição cognitiva analisando a interseção dos resultados do Mini Exame do Estado Mental (Mini Mental) (B9) com as respostas do Pfeffer Functional Activities Questionnaire (QPAF) (B11), a fim de se obter maior fidedignidade no resultado para avaliação cognitiva. Ou seja, aqueles idosos que obtiveram 12 ou menos pontos no Mini Mental $\underline{e} 6$ ou mais pontos no Pfeffer.

\section{- Seção C - Estado de Saúde}

- Hipertensão arterial referida (C4), diabetes referida (C5), câncer referido (C6), doença crônica do pulmão referida (C7), doenças cardíacas referida (C8), doença cerebrovascular referida (C9), doença ósteo-articular referida (C10), quedas (C11a), doença psiquiátrica referida (C20), Escala de Depressão Geriátrica (C21). 
- Seção D - Estado Funcional

- Dificuldade para atravessar quarto caminhando (D11), dificuldade para: vestir-se (D13a), banhar-se (D14a), alimentação (D15a), levantar-se ou deitar-se na cama (D16a), utilizar banheiro (D17a), cozinhar (D18a), cuidar do dinheiro (D19a), ir a lugares sozinhos (D20a), comprar alimentos (D21a), telefonar (D22a), tarefas domésticas leves (D23a), tarefas pesadas da casa (D24a), tomar remédios (D25a), recebe ajuda (D26); relação do ajudante com o idoso entrevistado (D26b).

- Seção H - História de Trabalho e Fontes de Receita

- Situação atual de trabalho (H21), razão pela qual trabalha atualmente $(\mathrm{H} 22)$, fonte de receita $(\mathrm{H} 26)$, quantia de receita $(\mathrm{H} 27 \mathrm{a}, \mathrm{H} 27 \mathrm{~b})$, receita é suficiente para cobrir despesas diárias $(\mathrm{H} 30)$.

- Seção K - Antropometria

- Índice de massa corporal.

O critério de inclusão para os questionários que foram utilizados nesse estudo foram as respostas positivas para PCF 1, o que totalizou um número expandido de 9.479 , apresentado nos resultados.

É importante referir que todas as tabelas apresentadas a seguir neste estudo estão relacionadas ao Estudo SABE, no município de São Paulo, no ano 2.000. Por essa razão, essa informação não será colocada no título das tabelas. 
RESULTADOS e DISCUSSÃO 
$\mathrm{Na}$ população de 2.143 idosos desse estudo, verifica-se a existência de $1,1 \%$ de pessoas com sinais positivos para a violência, o que corresponde a 31 entrevistas, conforme o critério adotado e descrito anteriormente. Fazendo-se a expansão desse número para a população do Município de São Paulo, de acordo com a metodologia de amostra já apresentada, presume-se que haja 9.479 pessoas com possível sinal de violência. Entre estes a maior proporção relaciona-se ao sexo feminino, independente de serem mais numerosos na população (Tabela 1).

Tabela 1 - Distribuição dos idosos com suposto sinal de violência, segundo algumas variáveis.

\begin{tabular}{|c|c|c|c|}
\hline Variável & $\mathbf{N}^{0}$ & $\%$ & $\begin{array}{l}\text { Coeficiente de } \\
\text { prevalência (\%o) }\end{array}$ \\
\hline \multicolumn{4}{|l|}{ Sexo } \\
\hline Feminino & 6925 & 73,1 & 14,0 \\
\hline Masculino & 2554 & 26,9 & 7,0 \\
\hline \multicolumn{4}{|l|}{ Idade } \\
\hline 60 a 74 anos & 5334 & 56,3 & 8,0 \\
\hline $75 e+$ & 4145 & 43,7 & 22,0 \\
\hline \multicolumn{4}{|l|}{ Escolaridade } \\
\hline 0 a 4 anos de estudo & 6740 & 71,1 & 10,0 \\
\hline 5 a 10 anos de estudo & 1357 & 14,3 & 17,0 \\
\hline $11 \mathrm{e}+$ anos de estudo & 1205 & 12,7 & 12,0 \\
\hline \multicolumn{4}{|l|}{ Estado marital } \\
\hline Casado & 2177 & 23,0 & 5,0 \\
\hline Divorciado/separado & 2599 & 27,4 & 36,0 \\
\hline Viúvo & 2788 & 29,4 & 11,0 \\
\hline Solteiro & 1915 & 20,2 & 47,0 \\
\hline Total & 9479 & ----- & 11,0 \\
\hline
\end{tabular}

Segundos diversos relatos, desde a antiguidade essa dinâmica é observada pelo maior respeito ao homem que envelhece, por ser 0 detentor de sabedoria ${ }^{(12)}$. Em algumas culturas, como na África subsaariana, as mulheres idosas têm sua sabedoria e experiência compreendidas como bruxaria e sofrem as conseqüências violentas de tal acusação $^{(5)}$. Esse padrão de vulnerabilidade se mantém, como mostram pesquisas mais atuais ${ }^{(27,35,37,48)}$ e, muitas vezes, associa-se a relatos de violência contra mulher em períodos antecessores ao envelhecimento, o que leva a refletir a questão da relação dos casos de violência doméstica 
em contexto amplo: essas mulheres vitimizadas na juventude poderão ser as idosas violentadas no futuro.

A faixa etária predominante foi a de 60 a 74 anos, pois essa foi também a maior porcentagem de idosos. Porém, ao se considerar o coeficiente de prevalência para violência, a faixa etária mais vulnerável é a 75 e mais anos: $22,0 \%$ (Tabela 1 ).

Essa faixa etária é mais vulnerável ao risco de violência e os idosos com idade predominante em 80 anos e mais, mulheres e viúvas são os mais vulneráveis, como discutem Souza et al ${ }^{(49)}$. Esses mesmos dados foram observados em publicações do INPEA ${ }^{(22)}$, nos estudos de Alonso $^{(31)}$ e Gaioli ${ }^{(62)}$.

A análise da prevalência de demência, que dobra a cada cinco anos de aumento da idade, subindo de $3 \%$ aos 70 anos para 20 a $30 \%$ aos 85 anos $^{(25)}$, é observação interessante que sugere, indiretamente, situação de violência com o aumento da idade. Idosos demenciados podem sofrer maior risco de violência por abandono, abusos físicos ou maus tratos ${ }^{(51)}$.

Ainda na tabela 1 , a baixa escolaridade - $71,1 \%$ - parece ser um risco à vulnerabilidade da violência. É interessante observar que nos estudos sobre violência, a escolaridade do idoso é pouco ressaltada. Talvez pelo predomínio da baixa escolaridade entre o atual grupo de idosos; porém, considera-se a relevância da inserção de tal característica nas pesquisas, pois a escolaridade está relacionada ao tipo de receita e sustento que esse idoso terá e, provavelmente, à suposta associação com alguns dos tipos de violência referidos pela OMS.

Ao considerar o estado civil, os idosos mais vulneráveis à violência são os solteiros $(47,0 \%$ ) seguidos pelos divorciados ou separados $(36,0 \%$ ) (Tabela 1).

Em diversas pesquisas citadas anteriormente ${ }^{(22,33,49,62)}$ os dados encontrados relacionam a violência contra o idoso à viuvez que, neste caso, teve as taxas mais baixas, o que faz dessa informação um dado inédito. Esses idosos teriam algum fator especial de exclusão, como por exemplo, perda de visão, maior dependência física que, 
consequentemente, traria maior risco para sofrer violência; essa é mais uma questão para reflexão.

Assim, os idosos com suposta condição de violência no Estudo SABE, caracterizam-se por ter idade avançada, baixa escolaridade, ser do sexo feminino e estado civil solteiro.

Em relação aos dados do estado cognitivo do idoso foram utilizados os resultados da avaliação do Mini Exame do Estado Mental (MEEM), realizado com o idoso e do Questionário Pfeffer, realizado com o cuidador dos idosos que não atingiam o escore mínimo de 12 pontos no Mini Mental.

Dessa forma, os idosos que obtiveram pontuação igual ou menor a 12 foram considerados como portadores de perda cognitiva, embora tal diagnóstico dependa de exames médicos e neuropsicológicos mais específicos ${ }^{(78)}$.

No Questionário Pfeffer, os resultados com escore $\geq 6$ também indicaram idosos com dependência decorrente de possíveis quadros demenciais ${ }^{(78)}$. A análise desses resultados em conjunto permite uma visão da população com indicativo de perda cognitiva no Estudo SABE (Tabelas 2, 3, 4 e 5). 
Tabela 2 - Distribuição dos idosos em relação à condição cognitiva (segundo Mini Mental) e possível sinal de violência.

\begin{tabular}{|c|c|c|c|c|c|c|}
\hline \multirow{3}{*}{ Mini Mental } & \multicolumn{6}{|c|}{ Sinal de violência } \\
\hline & \multicolumn{2}{|c|}{ Sim } & \multicolumn{2}{|c|}{ Não } & \multicolumn{2}{|c|}{ Total } \\
\hline & $\mathbf{N}^{\mathbf{0}}$ & $\%$ & $\mathbf{N}^{\mathbf{0}}$ & $\%$ & $\mathbf{N}^{\mathbf{0}}$ & $\%$ \\
\hline$\geq 13$ & 7008 & 1,0 & 722103 & 99,0 & 729111 & 100,0 \\
\hline$\leq 12$ & 1334 & 2,5 & 52797 & 97,5 & 54131 & 100,0 \\
\hline
\end{tabular}

Tabela 3 - Distribuição dos idosos com possível sinal de violência e condição cognitiva, segundo Mini Mental.

\begin{tabular}{|c|c|c|c|c|c|c|}
\hline \multirow{3}{*}{ Sinal de Violência } & \multicolumn{6}{|c|}{ Mini Mental } \\
\hline & \multicolumn{2}{|c|}{$\geq 13$} & \multicolumn{2}{|c|}{$\leq 12$} & \multicolumn{2}{|c|}{ Total } \\
\hline & $\mathbf{N}^{\circ}$ & $\%$ & $\mathbf{N}^{\mathbf{0}}$ & $\%$ & $\mathbf{N}^{\mathbf{0}}$ & $\%$ \\
\hline Sim & 7008 & 84,0 & 1334 & 16,0 & 8342 & 100,0 \\
\hline Não & 722103 & 93,2 & 52797 & 6,8 & 774900 & 100,0 \\
\hline
\end{tabular}

A relação entre declínio cognitivo e sinal de violência é interessante para discussão pois, independente do sentido da análise dos dados (tabelas 2 e 3), nota-se indicação de associação forte entre declínio cognitivo e violência.

A dificuldade reside na identificação da causa e efeito dessa relação. Nesse estudo, não é possível reconhecer se casos de demência antecedem situações de violência ou se a violência traz seqüelas de perda cognitiva. Porém, é fato que, nas duas situações, há indícios dessa associação, já que em 2,5\% dos idosos com Mini Mental igual ou menor a 12 existe sinal de violência e em 16,0\% dos idosos com sinal de violência, o Mini Mental resulta igual ou menor a12, também.

Esses dados de declínio cognitivo se confirmam ao analisar as tabelas 4 e 5 , a seguir. 
Tabela 4 - Distribuição dos dados de avaliação do cuidador, segundo Pfeffer e possível sinal de violência.

\begin{tabular}{|c|c|c|c|c|c|c|}
\hline \multirow{3}{*}{ Pfeffer } & \multicolumn{6}{|c|}{ Sinal de violência } \\
\hline & \multicolumn{2}{|c|}{ Sim } & \multicolumn{2}{|c|}{ Não } & \multicolumn{2}{|c|}{ Total } \\
\hline & $\mathbf{N}^{0}$ & $\%$ & $\mathbf{N}^{\mathbf{0}}$ & $\%$ & $\mathbf{N}^{\mathbf{O}}$ & $\%$ \\
\hline$\geq 6$ & 1479 & 2,0 & 72957 & 98,0 & 74436 & 100,0 \\
\hline$\leq 5$ & 993 & 3,1 & 31301 & 96,9 & 32294 & 100,0 \\
\hline
\end{tabular}

Tabela 5 - Distribuição dos dados dos idosos com possível sinal de violência e a avaliação do cuidador, segundo Pfeffer

\begin{tabular}{|c|c|c|c|c|c|c|}
\hline \multirow{3}{*}{$\begin{array}{l}\text { Sinal de } \\
\text { Violência }\end{array}$} & \multicolumn{6}{|c|}{ Pfeffer } \\
\hline & \multicolumn{2}{|c|}{$\geq 6$} & \multicolumn{2}{|c|}{$\leq 5$} & \multicolumn{2}{|c|}{ Total } \\
\hline & $\mathbf{N}^{0}$ & $\%$ & $\mathbf{N}^{0}$ & $\%$ & $\mathbf{N}^{0}$ & $\%$ \\
\hline Sim & 1479 & 59,8 & 993 & 40,2 & 2472 & 100,0 \\
\hline Não & 72957 & 70,0 & 31301 & 30,0 & 104258 & 100,0 \\
\hline
\end{tabular}

Embora no total de idosos não predomine a dependência do cuidador para os casos com sinal de violência, se a observação for realizada comparativamente aos idosos que são dependentes de cuidadores, verificam-se dados importantes: 2,0\% desses idosos que dependem de cuidados apresentam sinal de violência. $E$ na avaliação da situação inversa, $59,8 \%$ dos idosos com sinal de violência apresentam necessidade de um cuidador.

É interessante verificar que o Questionário Pfeffer somente foi aplicado aos cuidadores dos idosos que apresentaram no Mini Mental resultado igual ou menor do que 12; assim, os $16,0 \%$ de idosos que tiveram sinal de violência e declínio cognitivo, foram os idosos do grupo que foi submetido ao Pfeffer, e então 59,8\% têm indícios de dependência por declínio cognitivo.

Ou seja, embora o número de idosos com declínio cognitivo e sinal de violência, neste estudo, seja reduzido em relação à sua população total, o que se discute aqui é a vulnerabilidade do idoso ao risco de violência, ao qual o indivíduo demenciado está exposto. 
Esse dado foi confirmado em diversas pesquisas ${ }^{(34,49,50,51)}$, pois traz a perda da autonomia, criando situações de dependência e necessidade de cuidados específicos. O cuidado demandado dessa situação, muitas vezes, na sociedade atual não é adequadamente atendido, pois a estrutura familiar sofreu modificações e nem sempre existem familiares disponíveis para cuidar desse idoso demenciado ${ }^{(57,58,71,72)}$. Dessa forma, o limite entre violência e dificuldade para cuidar torna-se frágil e tênue, fazendo necessária a pesquisa nessa área, para identificação das dificuldades e desenvolvimento de protocolos de prevenção e identificação de sinais de violência, principalmente em casos relacionados à demência.

$\mathrm{Na}$ análise das variáveis, outra questão importante relaciona-se ao estado de saúde do idoso. A relação entre as principais doenças referidas e a existência de sinal de violência foi avaliada na tabela 6 .

Tabela 6 - Distribuição das doenças referidas e possível sinal de violência.

\begin{tabular}{|c|c|c|c|c|c|c|}
\hline \multirow{3}{*}{ Doenças referidas } & \multicolumn{6}{|c|}{ Sinal de violência } \\
\hline & \multicolumn{2}{|c|}{ Sim } & \multicolumn{2}{|c|}{ Não } & \multicolumn{2}{|c|}{ Total } \\
\hline & $\mathbf{N}^{\circ}$ & $\%$ & $\mathrm{~N}^{\circ}$ & $\%$ & $\mathrm{~N}^{\circ}$ & $\%$ \\
\hline Hipertensão & 4910 & 51,8 & 440974 & 53,5 & 445884 & 53,3 \\
\hline Diabetes & 1265 & 13,3 & 148123 & 17,9 & 149388 & 17,9 \\
\hline Câncer & 116 & 1,2 & 27508 & 3,3 & 27624 & 3,3 \\
\hline Doença pulmão & 263 & 2,8 & 101770 & 12,3 & 102033 & 12,2 \\
\hline Doença coração & 1691 & 17,8 & 161495 & 19,5 & 163186 & 19,5 \\
\hline Doença neurológica & 1279 & 13,5 & 58964 & 7,1 & 60243 & 7,2 \\
\hline Doença reumática & 3302 & 34,8 & 262082 & 31,7 & 265384 & 31,7 \\
\hline Queda & 4532 & 47,8 & 234358 & 28,3 & 238889 & 28,6 \\
\hline Doença psiquiátrica & 2392 & 25,2 & 127539 & 15,4 & 129931 & 15,5 \\
\hline
\end{tabular}

Ao avaliar as diferentes doenças referidas por esses idosos verifica-se, quando comparadas à população com sinal de violência e à população geral, a predominância de casos de doenças neurológicas $(13,5 \%)$, reumáticas $(34,8 \%)$, quedas $(47,8 \%)$ e doenças psiquiátricas $(25,2 \%)$ para idosos com sinal de violência. 
Esse fato permite referir, cuidadosamente, a possibilidade de as outras doenças servirem de fator de proteção ao idoso contra sinal de violência e as doenças que causam maior dependência física e cognitiva, aumentarem o fator de risco para sinal de violência.

É sabido que as doenças neurológicas e reumáticas se não tratadas adequadamente trazem perda da autonomia física e cognitiva, causando inclusive dependência. Para alguns estudiosos, o idoso dependente é mais vulnerável à violência, pois a perda da autonomia cria a necessidade de outra pessoa realizar as atividades para o idoso e, conseqüentemente, dá poder a essa pessoa para determinar toda a rotina seguida pelo idoso dependente ${ }^{(49,55)}$. Daí, o risco de situações violentas se estabelecerem aumenta consideravelmente, pois além da violência explícita, há o risco da violência velada, quando o agressor acredita estar fazendo o melhor para o idoso ${ }^{(31)}$.

Tal condição é discutida também nas doenças psiquiátricas, que assim como os quadros depressivos ou demenciais, traz para o idoso limitação cognitiva e social conforme já descrito anteriormente.

Mas há nesse quadro de doenças referidas pelo idoso um dado alarmante, que não é uma doença diretamente, mas pode ocasionar seqüela e perda de autonomia tão grave quanto o que foi discutido: as quedas $(47,8 \%)$.

A análise específica do número de quedas sofridas pelos idosos, no período de 12 meses, observa-se na tabela 7 : 
Tabela 7 - Possível sinal de violência e número de quedas nos últimos 12 meses, entre os que referiram quedas.

\begin{tabular}{|c|c|c|c|c|}
\hline \multirow{3}{*}{$N^{0}$ de quedas } & \multicolumn{4}{|c|}{ Sinal de Violência } \\
\hline & \multicolumn{2}{|c|}{ Sim } & \multicolumn{2}{|c|}{ Não } \\
\hline & $\mathbf{N}^{0}$ & $\%$ & $\mathbf{N}^{0}$ & $\%$ \\
\hline 1 & 2124 & 46,9 & 134511 & 57,4 \\
\hline 2 & 422 & 9,3 & 40814 & 17,4 \\
\hline 3 & 867 & 19,1 & 24764 & 10,6 \\
\hline 4 & $\bar{L}$ & 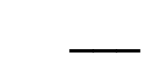 & 8989 & 3,8 \\
\hline 5 & 431 & 9,5 & 6843 & 2,9 \\
\hline 6 & & 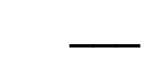 & 1663 & 0,7 \\
\hline 7 & 599 & 13,2 & 538 & 0,2 \\
\hline 8 & 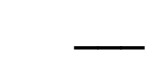 & 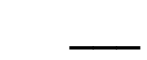 & 998 & 0,4 \\
\hline 10 & & & 3381 & 1,4 \\
\hline 12 & 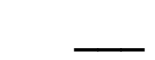 & 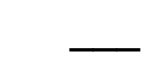 & 850 & 0,4 \\
\hline 15 & 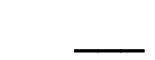 & $\longrightarrow$ & 1262 & 0,5 \\
\hline 20 & & & 1467 & 0,6 \\
\hline Não Sabem & 89 & 2,0 & 8276 & 3,5 \\
\hline Total & 4532 & 100,0 & 234356 & 100,0 \\
\hline
\end{tabular}

Para melhor análise dessa informação, a tabela 8 agrupa o número de quedas sofridas pelos idosos com sinal de violência e demonstra que 0 idoso submetido a 3 ou mais quedas no ano $(36,0 \%)$ tem maior risco de sofrer sinal de violência do que o idoso que sofre de 1 a 2 quedas, sendo que este pode estar mais protegido em relação ao risco de violência $(14,0 \%)$, 
Tabela 8 - Número de quedas no período de 12 meses e sinal de violência.

\begin{tabular}{c|rrrrrr}
\hline \multirow{2}{*}{$N^{*}$ de quedas } & \multicolumn{6}{|c}{ Sinal de violência } \\
\cline { 2 - 7 } & \multicolumn{2}{|c}{ Sim } & \multicolumn{2}{c}{ Não } & \multicolumn{2}{c}{ Total } \\
\cline { 2 - 7 } & \multicolumn{1}{|c}{$\mathbf{N}^{\circ}$} & \multicolumn{1}{c}{$\mathbf{N}^{\circ}$} & \multicolumn{1}{c}{$\%$} & $\mathbf{N}^{\circ}$ & $\%$ \% \\
\hline 0 & 4948 & 8,0 & 591808 & 992,0 & 596756 & 1000,0 \\
1 ou 2 & 2546 & 14,0 & 175326 & 986,0 & 177872 & 1000,0 \\
3 e + & 1986 & 36,0 & 50757 & 964,0 & 52653 & 1000,0 \\
\hline
\end{tabular}

Considerando as informações fornecidas pelo Sistema de Informações Hospitalares, em 2000, no Brasil, de que em 92.796 internações de idosos por causa externas, $52,1 \%$ ocorreram por queda e, dessas quedas, 1 em cada 3 foi fatal, há um um questionamento comum aos estudiosos da violência contra o idoso: seria a queda a violência contra o idoso ou decorrência de outro tipo de violência, como por exemplo, negligência com os cuidados no ambiente que esse idoso reside ${ }^{(16)}$.

Sethi ${ }^{(65)}$, em seus estudos na Europa, refere média de 72.000 idosos com mais de 80 anos morrendo anualmente por quedas. Ainda relata que, se ocorresse uma intervenção de prevenção, existiria uma redução de $51 \%$ nesse número de mortes.

Infelizmente esses dados são contabilizados, no Brasil, através das estatísticas de mortes e internações por causas externas ${ }^{(63)}$, quando o fato já está concretizado e, muitas vezes, irreversível para o idoso que sofreu a queda. A falta de dados sobre incidência e prevalência da violência contra o idoso no Brasil demonstra a vulnerabilidade ao qual o mesmo se expõe. O Ministério da Saúde e pesquisadores da violência ${ }^{(38,43)}$ atentam para a situação que esses idosos passam: quando não falecem, são operados e muitos se tornam dependentes de cuidados de terceiros, o que onera o sistema de saúde pública, diminui a esperança de vida com qualidade e autonomia desses idosos.

No que se refere aos casos de depressão do idoso, se a análise for dos dados dos idosos que supostamente desenvolveram a depressão antes de possíveis situações de violência (tabela 9), verifica-se que os 
idosos com quadro depressivo grave são mais vulneráveis ao risco de sofrer violência doméstica ( $8,3 \%)$. Isso pode ser justificado pelo fato de a depressão grave debilitar e trazer uma conseqüência quase tão séria quanto a dependência causada pela perda da autonomia física. Sem considerar o fato de que essa depressão pode se relacionar a quadro de perda física também.

Alguns autores discutem quadros depressivos como risco para vulnerabilidade a sofrer violência( ${ }^{(33,51,66)}$, muitas vezes identificados pelo isolamento social que o idoso pode referir.

Essa mesma questão pode ser observada pela violência antecedendo o quadro depressivo e, então, há predomínio de idosos com quadro de depressão leve (29,0\%), conforme descrito na tabela 10. Esse aspecto de avaliação é interessante porque há a possibilidade de essa depressão ser decorrente da violência sofrida e, portanto, auxiliaria o profissional de saúde a suspeitar de casos de violência, como proposto por diferentes estudos ${ }^{(38,39,67,68)}$.

Atenta-se, também, para a análise das questões utilizadas para identificação desse quadro depressivo, oriundas da Escala Geriátrica de Depressão. Embora o resultado predominante seja depressão leve, questões como "sinto minha vida vazia" obtiveram $56,7 \%$ de respostas positivas, "tenho abandonado meus interesses", 33,2\%, "estou aborrecido freqüentemente", $57,5 \%$, "prefiro ficar em casa", $46,0 \%$, demonstrando que esse idoso está envelhecendo sem qualidade de vida satisfatória.

Tabela 9 - Distribuição dos idosos com indicativo de depressão e possível sinal de violência.

\begin{tabular}{l|cccccc}
\hline \multirow{2}{*}{ Depressão } & \multicolumn{5}{|c}{ Sinal de violência } \\
\cline { 2 - 7 } & \multicolumn{3}{|c}{ Sim } & \multicolumn{2}{c}{ Não } & \multicolumn{2}{c}{ Total } \\
\cline { 2 - 7 } & $\mathbf{N}^{\mathbf{0}}$ & $\mathbf{\%}$ & $\mathbf{N}^{\mathbf{0}}$ & \multicolumn{1}{c}{$\%$} & $\mathbf{N}^{\mathbf{0}}$ & $\mathbf{\%}$ \\
\hline Normal - sem depressão & 2533 & 0,4 & 610241 & 99,6 & 612774 & 100,0 \\
Depressão leve & 2748 & 2,4 & 113900 & 97,6 & 116648 & 100,0 \\
Depressão grave & 2221 & 8,3 & 24522 & 91,7 & 26743 & 100,0 \\
\hline
\end{tabular}


Tabela 10 - Distribuição dos idosos com possível sinal de violência e indicativo de depressão.

\begin{tabular}{l|rrrr}
\hline \multirow{2}{*}{ Depressão } & \multicolumn{4}{|c}{ Sinal de Violência } \\
\cline { 2 - 5 } & \multicolumn{3}{|c}{ Sim } & \multicolumn{3}{c}{ Não } \\
\cline { 2 - 5 } & \multicolumn{1}{|c}{$\mathbf{N}^{\mathbf{0}}$} & \multicolumn{1}{c}{$\mathbf{N}^{\mathbf{0}}$} & \multicolumn{1}{c}{$\%$} \\
\hline Normal - sem depressão & 2533 & 26,7 & 610241 & 73,8 \\
Depressão leve & 2748 & 29,0 & 113900 & 13,8 \\
Depressão grave & 2221 & 23,4 & 24522 & 3,0 \\
NR & 1977 & 20,9 & 78062 & 9,4 \\
\hline Total & 9479 & 100,0 & 826725 & 100,0 \\
\hline
\end{tabular}

Por esse fato, no processo de envelhecimento, quadros de depressão leve, isolamento social, desinteresse, apatia são pertinentes à maior investigação por parte dos profissionais de saúde, que podem, inclusive, se valer de escalas de rastreio para avaliação de casos de violência, muitas vezes identificados pela alteração emocional demonstrada pelos idosos ${ }^{(67,68)}$.

A discussão da seção relacionada ao estado funcional do idoso traz importantes dados para o estudo, pois há, nessa observação do idoso, relacionada a violência doméstica, um dos indicativos esclarecedores para maiores pesquisas. Os diferentes protocolos de investigação da independência do idoso, como o próprio questionário Pfeffer utilizado no estudo $\mathrm{SABE}^{(78)}$, podem fornecer dados que esclarecem sobre a autonomia desse idoso. 
Tabela 11 - Distribuição dos idosos com dificuldade para AVD/AIVD e possível sinal de violência.

\begin{tabular}{|c|c|c|c|c|c|c|c|}
\hline & \multirow{3}{*}{ AVD/AIVD } & \multicolumn{6}{|c|}{ Sinal de violência } \\
\hline & & \multicolumn{2}{|c|}{ Sim } & \multicolumn{2}{|c|}{ Não } & \multicolumn{2}{|c|}{ Total } \\
\hline & & $\mathbf{N}^{\circ}$ & $\%$ & $\mathrm{~N}^{\circ}$ & $\%$ & $\mathbf{N}^{\circ}$ & $\%$ \\
\hline \multirow{7}{*}{$\begin{array}{c}\text { Ativ } \\
\text { ida } \\
\text { des } \\
\text { bás } \\
\text { ica } \\
\text { s }\end{array}$} & Atravessar quarto & 1523 & 3,3 & 444099 & 6,7 & 45932 & 100,0 \\
\hline & caminhando & & & & & & \\
\hline & Vestir-se & 2142 & 1,9 & 111106 & 98,1 & 113248 & 100,0 \\
\hline & Tomar banho & 1763 & 3,1 & 55687 & 96,9 & 57450 & 100,0 \\
\hline & Comer & 474 & 1,6 & 29695 & 98,4 & 30169 & 100,0 \\
\hline & Deitar/levantar da cama & 1244 & 1,6 & 78649 & 98,4 & 79893 & 100,0 \\
\hline & Ir ao banheiro & 1094 & 2,7 & 39643 & 97,3 & 40737 & 100,0 \\
\hline \multirow{9}{*}{$\begin{array}{l}\text { Ativ } \\
\text { ida } \\
\text { des } \\
\text { inst } \\
\text { rum } \\
\text { ent } \\
\text { ais }\end{array}$} & Preparar refeição quente & 1225 & 2,7 & 44895 & 97,3 & 46120 & $\overline{100,0}$ \\
\hline & Cuidar do próprio dinheiro & 780 & 1,1 & 69285 & 98,9 & 70065 & 100,0 \\
\hline & Ir a outros lugares sozinho & 2410 & 1,4 & 164307 & 98,6 & 166717 & 100,0 \\
\hline & Fazer compras de & 1623 & 1,4 & 117883 & 98,6 & 119506 & 100,0 \\
\hline & $\begin{array}{l}\text { alimentos } \\
\text { Telefonar }\end{array}$ & 1499 & 1,6 & 89902 & 98,4 & 91401 & 100,0 \\
\hline & Fazer tarefas domésticas & 1088 & 3,0 & 35102 & 97,0 & 36190 & 100,0 \\
\hline & leves & & & & & & \\
\hline & Fazer tarefas domésticas & 1204 & 1,0 & 121568 & 99,0 & 122772 & 100,0 \\
\hline & Tomar seus remédios & 1313 & 1,7 & 77547 & 98,3 & 78860 & 100,0 \\
\hline
\end{tabular}


Tabela 12 - Distribuição dos idosos com possível sinal de violência e dificuldade para AVD/AIVD.

\begin{tabular}{|c|c|c|c|c|c|c|c|}
\hline & \multirow{3}{*}{ AVD/AIVD } & \multicolumn{6}{|c|}{ Sinal de violência } \\
\hline & & \multicolumn{2}{|c|}{ Sim } & \multicolumn{2}{|c|}{ Não } & \multicolumn{2}{|c|}{ Total } \\
\hline & & $\mathrm{N}^{\circ}$ & $\%$ & $\mathrm{~N}^{\circ}$ & $\%$ & $\mathrm{~N}^{\circ}$ & $\%$ \\
\hline \multirow{7}{*}{$\begin{array}{l}\text { Ati } \\
\text { vid } \\
\text { ad } \\
\text { es } \\
\text { bá } \\
\text { sic } \\
\text { as }\end{array}$} & Atravessar quarto & 1523 & 16,1 & 44409 & 5,4 & 45932 & 5,5 \\
\hline & caminhando & & & & & & \\
\hline & Vestir-se & 2142 & 22,6 & 111106 & 13,4 & 113248 & 13,5 \\
\hline & Tomar banho & 1763 & 18,6 & 55687 & 6,7 & 57450 & 6,9 \\
\hline & Comer & 474 & 5,0 & 29695 & 3,6 & 30169 & 3,6 \\
\hline & Deitar / levantar da cama & 1244 & 13,1 & 78649 & 9,5 & 79893 & 9,6 \\
\hline & Ir ao banheiro & 1094 & 11,5 & 39643 & 4,8 & 40737 & 4,9 \\
\hline Ati & Preparar refeição quente & 1225 & 12,9 & 44895 & 5,4 & 46120 & 5,5 \\
\hline \multirow{3}{*}{$\begin{array}{l}\text { vid } \\
\text { ad } \\
\text { es }\end{array}$} & Cuidar do próprio dinheiro & 780 & 8,2 & 69285 & 8,4 & 70065 & 8,4 \\
\hline & Ir a outros lugares & 2410 & 25,4 & 164307 & 19,9 & 166717 & 19,9 \\
\hline & sozinho & 1602 & 171 & $11700 ?$ & $11^{2}$ & 110506 & \\
\hline \multirow{2}{*}{$\begin{array}{l}\text { ins } \\
\text { tru }\end{array}$} & alimentos & & & & ט, דו & & , \\
\hline & Telefonar & 1499 & 15,8 & 89902 & 10,9 & 91401 & 10,9 \\
\hline \multirow{2}{*}{$\begin{array}{c}\text { me } \\
\text { nt }\end{array}$} & Fazer tarefas domésticas & 1088 & 11,5 & 35102 & 4,2 & 36190 & 4,3 \\
\hline & leves & 1001 & 127 & 121560 & 117 & 10277 & 117 \\
\hline \multirow{2}{*}{ ais } & 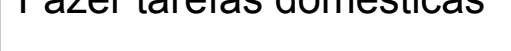 & 1204 & $1<, r$ & 121000 & $14, r$ & 122112 & $14, r$ \\
\hline & Tomar seus remédios & 1313 & 13,9 & 77547 & 9,4 & 78860 & 9,4 \\
\hline
\end{tabular}


Nos atuais instrumentos inseridos em protocolos de rastreio para violência contra o idoso, uma das bases avaliadas e checadas pelos profissionais de saúde é a questão da atividade funcional do mesmo ${ }^{(67,68)}$.

Neste estudo verificam-se duas formas de análise para essa questão: quando o idoso possui alguma dificuldade funcional, se está mais suscetível ao sinal de violência e o contrário, quando há algum sinal de violência, que tipo de dificuldade funcional esse idoso apresenta.

Embora sejam avaliados apenas sinais supostos de violência, é interessante verificar que a dificuldade funcional que pode estar relacionada ao sinal de violência, concentra-se em atividades de vida diária como locomover-se pelo quarto $(3,3 \%)$, tomar banho $(3,1 \%)$ e fazer tarefas domésticas leves $(3,0 \%)$, conforme apresentado na tabela 11 . Ou seja, esses idosos estão mais vulneráveis a sofrer algum sinal de violência.

Quando se avalia a situação inversa (tabela 12), para o idoso que teve algum sinal suposto de violência encontram-se dificuldades praticamente em todas as ações de rotina de vida diária.

A análise desses dados é de extremo valor, pois se discutem aqui as situações básicas mais do que para sua convivência social e, sim, sua sobrevivência.

Ao refletir que a população está envelhecendo, como divulgado pela $\mathrm{OMS}^{(5)}$ e o $\mathrm{IBGE}^{(3)}$, e parcela desses idosos sofrerá de doenças crônico-degenerativas ${ }^{(71,72)}$, em breve existirá uma demanda dessa população com necessidade de cuidadores para a realização de atividades de vida diária, porém a cultura brasileira ainda não visualiza essa necessidade. Conseqüentemente, não se responsabiliza por esses idosos que, independente de sofrerem violência, estarão necessitados de auxílio que já não recebem, como bem demonstrado no estudo $\operatorname{SABE}^{(78)}$, o que já permite reflexão sobre possível sinal de negligência, um tipo de violência contra o idoso.

Um outro aspecto interessante dessa seção é que os idosos que não recebem ajuda em suas atividades de vida diária, predominam quanto à presença de sinal de violência, $63,2 \%$, porém os que recebem 
ajuda de apenas uma pessoa, também constituem um grupo considerável, em relação aos demais, quando avaliados no suposto sinal de violência, 21,6\% (tabela 13).

Tabela 13 - Distribuição dos idosos com possível sinal de violência e o número de pessoas que lhe oferecem ajuda para suas atividades de vida diária.

\begin{tabular}{c|cccc}
\hline \multirow{2}{*}{ Recebe ajuda } & \multicolumn{4}{|c}{ Sinal de Violência } \\
\cline { 2 - 5 } & \multicolumn{3}{|c}{ Sim } & \multicolumn{3}{c}{ Não } \\
\cline { 2 - 5 } & $\mathbf{N}^{\mathbf{0}}$ & $\mathbf{\%}$ & $\mathbf{N}^{\mathbf{0}}$ & $\%$ \\
\hline Ninguém ajuda & 5987 & 63,2 & 584691 & 70,7 \\
1 pessoa & 2044 & 21,6 & 138216 & 16,7 \\
2 pessoas & 379 & 4,0 & 71611 & 8,7 \\
3 pessoas & 548 & 5,8 & 23355 & 2,8 \\
4 pessoas & 236 & 2,5 & 5035 & 0,6 \\
5 pessoas & - & - & 3097 & 0,4 \\
6 pessoas & - & - & - & $-10,1$ \\
7 pessoas & - & - & 428 & 0,0 \\
Não Responderam & 285 & 3,0 & - & - \\
\hline Total & 9479 & 100,0 & 826726 & 100,0 \\
\hline
\end{tabular}

Embora não seja um dado explícito neste estudo, tal condição demonstra a dificuldade em auxiliar o idoso encontrada por essa "uma pessoa" e não, propriamente, situação de violência intencional. É uma das condições mais limítrofes da violência nos dias atuais: há dificuldade em manter-se empregado, cuidar da própria família, realizar suas tarefas pessoais e inserir o idoso que necessita de auxílio nesse contexto. As famílias não mais possuem um membro que permaneça em casa para cuidar de seus idosos ${ }^{(57,58)}$. Muitas vezes, a melhor forma de cuidar desse idoso é deixá-lo em casa o dia inteiro, o que pode ser interpretado, pela lei, como uma forma de violência doméstica por omissão(25).

Talvez, aqui, seja o ponto crucial para as discussões sobre a violência contra o idoso: qual será o limiar entre violência e desinformação e como ensinar essa sociedade, que está envelhecendo, a cuidar de seus idosos. 
Em diversas pesquisas discute-se o reflexo dessas indagações. A violência que há relatada refere familiares próximos como os perpetradores do ato, tanto que os indicadores para identificação de agressores sempre referem filhos/as, genros e noras, netos/as como principais familiares de risco(30,49-51).

Esta situação não foi diferente neste estudo: na ajuda recebida nas suas dificuldades funcionais apresentadas, os idosos que receberam esse auxílio de seus filhos tiveram $49,8 \%$ de chance de apresentar sinal de violência, enquanto de seus genros e noras tiveram $28,8 \%$, de seus netos(as) $22,6 \%$, conforme apresentado na tabela 14 . Seria o caso de se discutir se essa agressão é intencional ou apenas uma questão de desinformação. É válido, ainda, acrescentar que os idosos que receberam ajuda de pessoas contratadas apresentaram $21,4 \%$ de sinal de violência, o que reitera a questão da nova estrutura familiar, que não insere o idoso em seu contexto.

Tabela 14 - Distribuição dos ajudantes do idoso com possível sinal de violência.

\begin{tabular}{l|cccc}
\hline \multirow{2}{*}{ Relacionamento } & \multicolumn{4}{|c}{ Sinal de Violência } \\
\cline { 2 - 5 } & \multicolumn{3}{|c}{ Sim } & \multicolumn{3}{c}{ Não } \\
\cline { 2 - 5 } & $\mathbf{N}^{\circ}$ & $\%$ & $\mathbf{N}^{\circ}$ & $\%$ \\
\hline Esposo(a) & 205 & 5,9 & 70680 & 29,2 \\
Filho(a) & 1738 & 49,8 & 179126 & 74,0 \\
Enteado(a) & & & 484 & 0,2 \\
Irmão/irmã & 562 & 16,1 & 11971 & 4,9 \\
Genro/nora & 1006 & 28,8 & 22083 & 9,1 \\
Neto(a) & 789 & 22,6 & 39331 & 16,3 \\
Outro familiar & 281 & 8,1 & 15867 & 6,6 \\
Outro não familiar & 296 & 8,5 & 16615 & 6,9 \\
Doméstica & 748 & 21,4 & 40849 & 16,9 \\
\hline Total & 5625 & 161,2 & 397006 & 164,1 \\
\hline
\end{tabular}

A questão financeira para o idoso é um dos aspectos determinantes para sua qualidade de vida, pois dará acesso aos serviços 
de saúde diferenciados, permitirá o uso de medicamentos, proporcionará a residência em casa própria, diminuirá a dependência de familiares e, supostamente, reduzirá seu risco para violência, já que diversas pesquisas apontam a questão financeira como um dos riscos mais sérios para a violência contra o idoso ${ }^{(50,51,53,55)}$.

Tabela 15- Distribuição da atual situação de trabalho do idoso com possível sinal de violência.

\begin{tabular}{l|cccc}
\hline \multirow{2}{*}{ Sinal de Violência } & \multicolumn{4}{|c}{ Trabalha atualmente } \\
\cline { 2 - 5 } & \multicolumn{3}{|c}{ Sim } & \multicolumn{3}{c}{ Não } \\
\cline { 2 - 5 } & $\mathbf{N}^{\circ}$ & $\%$ & $\mathbf{N}^{\circ}$ & $\%$ \\
\hline Sim & 1636 & 0,7 & 6818 & 1,2 \\
Não & 222455 & 99,3 & 553940 & 98,8 \\
\hline Total & 224091 & 100,0 & 560758 & 100,0 \\
\hline
\end{tabular}

Tabela 16- Distribuição dos idosos com possível sinal de violência e a razão pela qual trabalha hoje.

\begin{tabular}{l|cccc}
\hline \multirow{2}{*}{ Razão pelo trabalho atual } & \multicolumn{4}{|c}{ Sinal de Violência } \\
\cline { 2 - 5 } & \multicolumn{3}{|c}{ Sim } & \multicolumn{3}{c}{ Não } \\
\cline { 2 - 5 } & $\mathbf{N}^{\mathbf{0}}$ & $\%$ & $\mathbf{N}^{\mathbf{0}}$ & $\%$ \\
\hline Necessita do ganho & 624 & 38,1 & 153449 & 69,0 \\
Quer ajudar a família & - & - & 16743 & 7,5 \\
Quer manter-se ocupado & - & - & 13663 & 6,1 \\
Necessidade de sentir-se útil & - & - & 18021 & 8,1 \\
Gosto do meu trabalho & 1012 & 61,9 & 20578 & 9,3 \\
\hline Total & 1636 & 100,0 & 222454 & 100,0 \\
\hline
\end{tabular}


Tabela 17- Distribuição dos idosos com possível sinal de violência e sua renda total, apresentada em quintil.

\begin{tabular}{l|cccc}
\hline \multirow{2}{*}{ Renda total (em quintil) } & \multicolumn{4}{|c}{ Sinal de Violência } \\
\cline { 2 - 5 } & \multicolumn{3}{|c}{ Sim } & \multicolumn{3}{c}{ Não } \\
\cline { 2 - 5 } & $\mathbf{N}^{\circ}$ & $\%$ & $\mathbf{N}^{\circ}$ & $\%$ \\
\hline $1^{\circ}$ & 3130 & 38,3 & 181632 & 26,8 \\
$2^{\circ}$ & 1395 & 17,0 & 100915 & 14,9 \\
$3^{\circ}$ & 1844 & 22,5 & 128787 & 19,0 \\
$4^{\circ}$ & 1185 & 14,5 & 129287 & 19,1 \\
$5^{\circ}$ & 629 & 7,7 & 136226 & 20,1 \\
\hline Total & 8183 & 100,0 & 676847 & 100,0 \\
\hline
\end{tabular}

Tabela 18 - Coeficiente de sinal de violência segundo percepção de suficiência de renda

\begin{tabular}{|c|c|c|c|c|c|c|}
\hline \multirow{3}{*}{ Renda suficiente } & \multicolumn{6}{|c|}{ Sinal de Violência } \\
\hline & \multicolumn{2}{|c|}{ Sim } & \multicolumn{2}{|c|}{ Não } & \multicolumn{2}{|c|}{ Total } \\
\hline & $\mathbf{N}^{0}$ & $\%$ & $\mathbf{N}^{\circ}$ & $\%$ & $\mathbf{N}^{0}$ & $\%$ \\
\hline Sim & 1449 & 5,6 & 257073 & 994,4 & 258522 & 314,3 \\
\hline Não & 6767 & 12,1 & 557246 & 988,0 & 564013 & 685,7 \\
\hline
\end{tabular}

A maioria dos idosos não trabalha $(1,2 \%)$ e apresenta algum sinal de violência, sendo que 38,1\% têm esse indício de violência e dependem do trabalho para sobreviver (tabelas 15 e 16).

Entre os idosos que recebem receita, a maioria concentra-se no primeiro quintil de renda total (38,3\%) (Tabela 17). Mesmo com receita tão baixa e insuficiente para seus gastos esses idosos provêem suas próprias necessidades, como gastos com casa, comida, roupas, médicos, passeios ou transporte, sendo tal renda insuficiente para todas as despesas dos idosos com sinal de violência $(12,0 \%$ ) (Tabela 18).

Desta forma, dos idosos que tiveram suposto sinal para violência, a maioria não trabalha, mas dos que recebem receita de aposentadoria ou 
dos que trabalham, são os responsáveis pelos seus próprios gastos e, muitas vezes, ainda auxiliam familiares.

Acredita-se que a questão financeira seja um dos maiores riscos para a perpetração da violência, como divulgado nas pesquisas, pois na maioria dos casos, o idoso acredita estar beneficiando seu próximo e não percebe que, talvez, esse parente tenha mais idade e condições de buscar subsídio próprio(50,51,53,55).

Em relação à questão nutricional do idoso, considerou-se para essa análise os dados do índice de massa corporal (IMC) dos idosos que tinham resposta positiva para suposto sinal de violência, para verificação de estado nutricional como conseqüência de possível violência.

Tabela 19 - Idosos com possível sinal de violência segundo a distribuição de seu IMC.

\begin{tabular}{l|cccc}
\hline \multirow{2}{*}{\multicolumn{1}{c|}{ IMC }} & \multicolumn{4}{c}{ Sinal de Violência } \\
\cline { 2 - 5 } & \multicolumn{3}{|c}{ Sim } & \multicolumn{2}{c}{ Não } \\
\cline { 2 - 5 } & $\mathbf{N}^{\mathbf{0}}$ & $\%$ & $\mathbf{N}^{\circ}$ & $\%$ \\
\hline Baixa & 3648 & 38,5 & 173210 & 21,0 \\
Normal & 2316 & 24,4 & 314335 & 38,0 \\
Alta & 720 & 7,6 & 86095 & 10,4 \\
Obesidade & 1660 & 17,5 & 151227 & 18,3 \\
\hline Não Responderam & 1136 & 12,0 & 101857 & 12,3 \\
\hline Total & 9480 & 100,0 & 826724 & 100,0 \\
\hline
\end{tabular}

Ao considerar os idosos com sinal de suposta violência avaliados segundo seu IMC, tem-se a maioria na faixa baixa para estado nutricional, 38,5\% (Tabela 19). Porém, tal dado serve apenas para ilustrar a situação, uma vez que essa relação, para ser estabelecida, deve considerar diferentes variáveis, já que o idoso é mais suscetível a quadros de deficiência nutricional por interferência de doenças, condição cognitiva, próprios hábitos nutricionais, entre outras situações.

É interessante acrescentar, nessa discussão, os dados qualitativos relacionados à questão PCF 2, que determinava a descrição da situação de suposta violência observada pelas entrevistadoras. É válido referir que 
a análise do sinal de violência anotado foi realizada segundo a classificação sugerida pela $\mathrm{OMS}^{(5)}$.

Os dados estão apresentados em porcentagem simples, devido ao fato de 0 Estudo SABE não se destinar a inquerir violência especificamente. Portanto, servem de ilustração para as possíveis causas referidas dos sinais de violência observados.

Nessa avaliação qualitativa obtiveram-se 31 questionários, com os seguintes sinais de violência:

- Abuso financeiro/material: $17,2 \%$

- Abuso físico: $13,8 \%$

- Abuso psicológico: $55,1 \%$

- Abandono/negligência: $45,0 \%$

Com essa avaliação qualitativa é possível estimar que, na população de São Paulo, talvez seja maior a predominância de violência psicológica, com maior abandono e negligência do idoso.

Dessa forma, fica reforçada a importância do protocolo de violência inserido na próxima edição do Estudo SABE, que tornará possível a identificação desses idosos e qual a forma de violência encontrada. 
CONCLUSÃO 
A finalização da análise dos dados desse estudo permite identificar que os idosos vulneráveis ao risco de violência doméstica na cidade de São Paulo, em 2000, segundo o Estudo SABE realizado, concentram-se entre as mulheres, com idade avançada (75 e mais anos), baixa escolaridade e solteiras.

A condição cognitiva desses idosos é prejudicada, com possível declínio cognitivo, necessitando de auxílio de cuidador. Há predomínio de doenças limitantes, com perda de autonomia e independência, sendo que as quedas relacionam-se diretamente com o quadro de violência. Parece que quanto maior o número de quedas, maior a situação de violência doméstica.

Os idosos necessitam de ajuda nas atividades diárias, mas a maioria não recebe essa ajuda e seus possíveis perpetradores da violência concentram-se mais entre genros, noras e netos. São idosos que pouco trabalham, mas dos que trabalham, necessitam muito do ganho, que é insuficiente para a cobertura de suas despesas mensais.

A condição nutricional, que pode ser decorrente de casos de violência doméstica, predomina com baixo índice de massa corporal.

Assim, este estudo é mais um a mostrar a vulnerabilidade dos idosos da sociedade em relação ao risco de violência. Mas, o mais interessante nessa análise, é esse quadro resumido, acima discutido, que, se analisado cuidadosamente, refletirá diversas nuances de violência definida pela OMS: fala-se de negligência, abandono, abuso psicológico, financeiro.

Mas quem são esses idosos?

Isso já justifica o desenvolvimento de mais pesquisas no tema, mas quando se amplia essa questão e se projeta para a população de São Paulo, do Brasil ou mesmo no âmbito da discussão mundial, a responsabilidade é outra; passa-se a discutir políticas públicas, responsabilidade social, será dada aos idosos a condição médica de viver mais e a dignidade para que valha a pena viver mais.

Assim, a nova edição do Estudo SABE, já inseriu em seu questionário o protocolo específico de avaliação de violência doméstica e, 
em breve, ter-se-á acesso aos dados da população de São Paulo nesse tema.

Este estudo se propôs a traçar uma exploração preliminar do perfil dos idosos com hipótese de sofrer violência doméstica. Atingiu seus resultados na medida em que conseguiu rascunhar essa realidade. Cabe, agora, a continuidade desse trabalho, conscientizando a sociedade da mesma maneira como já aconteceu com a violência dirigida às mulheres e às crianças.

Lutar contra a violência ao idoso é desenvolver ainda mais a consciência de cidadania e aperfeiçoar políticas públicas que atendam a essa faixa, já significativa, de nossa população. 
5. REFERÊNCIAS BIBLIOGRÁFICAS 
1. Ramos, L.R., Veras, R.P., Kalache, A. Envelhecimento populacional: uma realidade brasileira - Rev. Saúde Pública, SP, 21: 211-24, 1987.

2. Berquó, ES. Fatores Estatísticos e dinâmicos - mortalidade e fecundidade. In: Santos, JLF, Levy, MSF, Szmrecsányi, T (orgs). Dinâmica da População.SP: TA Queiroz Editor; 1991; 21-86.

3. Oliveira JC, Albuquerque FRPC, Lins IB. Projeção da População Brasileira por Sexo e Idade para o Período 1.980 - 2.050: Instituto Brasileiro de Geografia e Estatística, Diretoria de Pesquisas, Coordenação de População e Indicadores Sociais; 2.004. Disponível em http://www.ibge.gov.br .

4. Pereira, R. Cresce a expectativa de vida do brasileiro e cai a mortalidade infantil. Jornal O Estado de São Paulo, 02/12/2005, pgs. A20 - Seção Vida, Coluna Demografia.

5. OMS. Organização Mundial de Saúde. Relatório Mundial sobre Violência e Saúde. 2002.

6. Kalache A, Veras RP, Ramos LR. O envelhecimento da população mundial. Um desafio novo. Rev.Saúde Pública, 1.987; 21(3): 20010.

7. Néri, A. L. Atitudes e crenças sobre a velhice: Análise de conteúdo de textos do Jornal O Estado de São Paulo publicados entre 1995 e 2002. In As múltiplas faces da velhice no Brasil, Simson, O. R. M., Néri, A. L. e Cachioni, M., Campinas, SP, Editora Alínea, 2003, Coleção Velhice e Sociedade.

8. Carvalho, J. A. M., Garcia, R. A. O envelhecimento da população brasileira: um enfoque demográfico. Cad. Saúde Pública, Rio de Janeiro, 19(3):725-733, mai-jun, 2003.

9. Suzman, R. The Structure of Successful Aging. Pan American Health Organization, June 14, 2002, Behavioral and Social Research Program National Institute on Aging, $\mathrm{NIH}$.

10. Veras, R. "Em busca de uma assistência adequada à saúde do idoso: revisão da literatura e aplicação de um instrumento de detecção precoce e de previsibilidade de agravos" Cad. Saúde Pública, RJ, 19(3), 705-715, mai-jun, 2003. 
11. Hudson, M. F. Elder Abuse and Neglect. Adult Literacy (NCAL) Technical Report TR99-01. Graduate School of Education, University of Pennsylvania for the Southcast, and Islands Regional Technology in Education Consortium, 1999. Disponível em www.seniornet.org.

12. Sousa, A. M. V. Tutela Jurídica do Idoso - A assistência e a convivência familiar, Alínea Editora, Campinas, SP, 2004.

13.R., K. OMS desenvolve programas contra maus-tratos a idosos. Jornal O Estado de São Paulo, 21/06/2005, São Paulo, SP.

14. Uchoa E. Contribuições da antropologia para uma abordagem das questões relativas à saúde do idoso. Cad. Saúde Pública, 2.003; 19(3): 849-853.

15. PAHO. El Maltrato de Las Personas Mayores. Capítulo 5, pgs 135 - 158, Informe Mundial sobre la violência y la salud.

16. Minayo, M. C. Violência contra idosos - $O$ avesso do respeito à experiência e à sabedoria. Brasília: Secretaria Especial dos Direitos Humanos, 2004.

17. Constituição Federal de 1988.

18. Alves A. M. A Construção Social da Violência Contra os Idosos. Centro de Referência e Documentação sobre Envelhecimento da Universidade Aberta da Terceira Idade - UnATI, Universidade do Estado do Rio de Janeiro - UERJ; Textos Envelhecimento, 2.001; 3(6).

19. Cartilha O Idoso e seus Direitos. Secretaria de Ação Comunitária e Cidadania, Conselho Municipal do Idoso, Prefeitura Municipal de Santos, Santos, 2002.

20. Malagutti, A. O. Delegacia do Idoso no âmbito da segurança pública - Consultoria Legislativa da Câmara dos Deputados, Consultor Legislativo da Área XVII, Segurança e Defesa Nacional, nota técnica, março 2000.

21. Estatuto do Idoso, 2003.

22. Imasso, S. - Procura pela Delegacia do Idoso cresce $99 \%$. Jornal o Estado de São Paulo, 29/12/2004, seção Vida, pág. A11. 
23. Costa P.L., Chaves P.G.S. A vivência Afetiva e a Violência Doméstica contra os Idosos [pesquisa]. Belo Horizonte, 2003.

24. Siqueira, L.E.A. Estatuto do Idoso de A a Z. Idéias \& Letras, Aparecida, SP, 2004.

25. Nelson, D. Violence against elderly people: a neglected problem. The Lancet, vol 360, October 5, 2002. Disponível em: www.thelancet.com.

26. Wolf, R. The Nature and Scope of Elder Abuse in Abuse and Neglect of Older People. Journal of the American Society on Aging, Generation Special Reprint, Summer 2000, 06-12.

27. Tatara, T. et al The National Elder Abuse Incidence Study - Final Report - Prepared for The Administration for Children and Families and The Administration on Aging in The U.S. Department of Health and Human Services by The National Center on Elder Abuse at The American Public Human Services Association* in Collaboration with Westat, Inc. - September 1998.

28. Dyer, C.B. et al - Texas Elder Abuse na Mistreatment Center. Spring 2004, Team Institute, Houston, Texas.

29. Ahmad, M.; Lachs, M.S. Elder abuse and neglect: What physicians can and should do. Cleveland Clinic Journal of Medicine. Vol. 69, number 10 , october 2002, 801-808.

30. Minayo MCS. Violência contra idosos: relevância para um velho problema. Cad. Saúde Pública, 2003; 19(3): 783-791.

31. Herrera AMM. Consideraciones sobre maltrato y violência en la vejez - A la luz de calidad de vida. Grupo Interdisciplinario sobre Envejecimiento, Universidad Nacional de Colombia, 2004.

32. Machado L., Gomes R., Xavier E., Report on Elder Abuse in Brazil. Institute of Gerontology Candido Mendes University (UCAM). World Health Organization (WHO), International Network for the Prevention of Elder Abuse (INPEA), 2001.

33. Lancet, 2004, 364: editorial. Vol. 364, n 9441, 02/10/04.

34. Wolf, R. S. Elder abuse and neglect: an update. Reviews in clinical Gerontology, 1997, 7:177-182. 
35.Phillips, L.R. Domestic violence and aging women. Geriatric Nursing, 2000. volume 21, number 4, 188-195.

36. Schraiber, L.B.; D'Oliveira, A.F.; França Jr, I.; Diniz, C.S.G.; Portela, A.P.; Ludermir, A.B.; Valença, O.; Couto, M.T. WHO Multi Country Study on Women's Health and Domestic Violence Against Women. Final Report. Brazil. São Paulo: FMUSP, 2002.

37. Keikeiame, J.; Ferreira. M. Mpathekombi, ya bantu abadala: Elder abuse in black townships on the Cape Flats. SAAWG Conference, 03/fevereiro/2001, pgs 07 a 11.

38. Mello Jorge, M.H.P.. Acidentes e Violências no Brasil: Breve Análise de suas Fontes de Dados in Cerqueira, D. e orgs. Fórum de Debates Criminalidade, Violência e Segurança Pública no Brasil: uma discussão sobre as Bases de Dados e Questões Metodológicas. $2^{\circ}$ Encontro: Crime e Relato II: Base de Dados da Saúde e Pesquisas de Vitimização. IPEA, Rio de Janeiro, agosto de 2000.

39. Wolf, R. Emotional distress and elder abuse. National Center on Elder Abuse Newsletter. December 1999 / January 2000.

40. Bernal, A.M; Gutièrrez, J.B. (coord.). Malos tratos a personas mayores: Guía de Actuación. Colección Manuales y Guías, Serie Persona Mayores, Observatorio de Personas Mayores, Ministerio de Trabajo y Asuntos Sociales, Secretaria de Estado de Servicios Sociales. Familias y Discapacidad, IMSERSO.

41. Ministro De Faria - Declaración de Toronto para la Prevención Global del Maltrato de las Personas Mayores, OMS, Universidad de Toronto y Universidad Ryerson, Notario, Canadá - Red Internacional de Prevención del Abuso y Maltrato en la Vejez, 2002. disponible em: www.who.int/hpr/ageing.

42. Mello Jorge, M. H. Violência como Problema de Saúde Pública in Ciência e Cultura - Temas e Tendências: Violência, Revista da Sociedade Brasileira para o Progresso da Ciência, ano 54, n. 1 , jul/ago/set, 2002, pgs $52-53$.

43. Ministério da Saúde. Política Nacional de Redução da Morbimortalidade por Acidentes e Violências: Portaria MS/GM $n^{\circ}$ 
737 de 16/5/01 publicada no DOU no 96 seção 1E, de 18/5/01 / Ministério da Saúde - Brasília: Ministério da Saúde, 2001.

44. Harbison, J., Morrow, M. Fórum: Re-examining the social construction of elder abuse and neglect: A Canadian perspective. Ageing and Society, 18, 1998, 691-711.

45. Zolotow, David. Violência, Familia y Tercera edad. Portal do Envelhecimento. Disponivel em www.pucsp.br/portaldoenvelhecimento/artieop/geral/artigo40.htm.

46. World Health Organization. Abuse of the elderly. 2002. Disponível: http://www.who.int/violence_injury_prevention.

47. Azevedo, M.A.N. Violência contra grupos específicos no Seminário: As Interfaces da Violência, Universidade Federal de São Paulo, 04 a 06 de agosto de 2005, SP, SP.

48. Ramos, L.R. Violência contra grupos específicos no Seminário: As Interfaces da Violência, Universidade Federal de São Paulo, 04 a 06 de agosto de 2005, SP, SP.

49. Souza, A. S; Meira, E. C; Néri, I. G.; Silva, J. A; Gonçalves, L. H. T. Fatores de risco de maus-tratos ao idoso na relação idoso/cuidador em convivência intra-familiar. Universidade Aberta da Terceira Idade, Textos Envelhecimento v. 7, n. 2, Rio de Janeiro, 2004.

50. Daichaman, L; Malks, B; Podnieks, E; Somers, S;Gutman, G. et al. Tool Kit to Raise Awareness on Elder Abuse. Taking Action: Step by Step. International Network for the Prevention of Elder Abuse, 2005.

51. Alonso, M. del C. F. Malos Tratos a Los Ancianos. Grupo de Salud Mental del PAPPS. Disponível em www.imsersomayores.csic.es.

52. Guedes, A. Violência contra idosos ocorre dentro de casa e parentes são os principais agressores. Portal Mais de 50. Disponível em: www.maisde50.com.br.

53. Néri A.L. Atitudes e Crenças sobre Velhice: Análise de Conteúdo de Textos do Jornal o Estado de São Paulo Publicados entre 1.995 e 2.002. In: Simson O.R.M., Neri A.L., Cachioni M. As Múltiplas Faces da Velhice no Brasil. São Paulo: Alínea Editora, 2.003. p. 1354. 
54. Scott E. Parceria na iniciativa contra a violência familiar no Canadá. Cad. de Saúde Pública, 1.994; 10 (01): 218-222.

55. Menezes, M.R. Da Violência Revelada à Violência Silenciada: um estudo etnográfico sobre a violência doméstica contra o idoso.Tese apresentada ao Programa Interunidades de Doutoramento em Enfermagem da Escola de Enfermagem de Ribeirão Preto da Universidade de São Paulo, sob orientação Profa ${ }^{a} r^{a}$ Amábile rodrigues Xavier Manco, Ribeirão Preto, SP, 1999.

56. Plouffe, L. A. - Addressing social and gender inequalities in health among seniors in Canadá. Cad. Saúde Pública, Rio de Janeiro, 19(3):855-860, mai-jun, 2003.

57. Veras RP, Ramos LR, Kalache A. Crescimento da população idosa no Brasil: Transformações e conseqüências na sociedade. Rev.Saúde Pública, 1.987; 21(3): 225-33.

58. Alvares, A.M. Situação dos idosos fragilizados no domicílio. Grupo de Ajuda mútua a familiares de idosos portadores da doença de Alzheimer. Disponível em: www.idosos.html.

59. Medeiros, J. Flagrante: Golpistas enganam idosos. Jornal O Estado de São Paulo, 23 de junho de 2005, Caderno Metrópole, C1 e C3.

60. Guerra H.L., Barreto S.M., Uchoa E., Firmo J.O.A., Costa M.F.F.L. A morte de idosos na Clínica Santa Genoveva, Rio de Janeiro: um excesso de mortalidade que o sistema público de saúde poderia ter evitado. Cad. de Saúde Publica, 2.000; 16 (2): 545-551.

61. Werneck, F. - Condenados donos de clínica no Rio onde morreram idosos. Jornal O Estado de São Paulo, 30/11/2005, seção Vida. Pág. A21.

62. Gaioli, C.C.L.O. Ocorrência de maus tratos em idosos no domicílio. Dissertação de mestrado apresentada à Escola de Enfermagem de Ribeirão Preto da Universidade de São Paulo. Orientadora: Rodrigues, R. A. P. Ribeirão Preto, 2004.

63. Gawryszewski VP, Mello Jorge MHP, Koizumi MS. Mortes e internações por causas externas entre os idosos no Brasil: 0 desafio de integrar a saúde coletiva e atenção individual. Rev. Associação Médica Brasileira, 2.004; 50(1): 97-103. 
64. Barbosa, R.M. As Múltiplas Faces da Violência: O Atendimento nos Serviços de Saúde. $1^{\circ}$ Congresso Paulista de Saúde Pública Saúde e Desenvolvimento, 22 a 26 de outubro de 2005, Santos, SP.

65. Sethi, D., Racioppi, F., Baumgarten, I., Vida, P. - Injuries and Violence in Europe - Why they matter and what can be done. Copenhagen, WHO Regional Office for Europe, 2002.

66. Lachs M.S., Pillemer K. Elder Abuse. Lancet, 2.004, 364 (9441): 1263-72.

67. Reis, M; Nahmiash, D. Validation of the Indicators of Abuse (IOA) Screen. The Gerontologist, vol. 38, nº 04, 471-480, 1998.

68. Reis, M. The IOA Screen: An Abuse-Alert Measure - That Dispels Myths in Abuse and Neglect of Older People. Journal of the American Society on Aging, Generation Special Reprint, Summer 2000, 13-16.

69. O'Brien, J. Screnning: A primary care clinician's perspective inBeall, S. C.; Baumhover,L. A. Abuse, Neglect, and Exploitation of Older Persons. British Library Cataloguing in Publication Data, 1996, Health Professions Press, Inc.51-64.

70. World Health Organization. International Network for the Prevention of Elder Abuse. Missing Voices, Vies of older persons on elder abuse.

71. Karsch, U. M. Idosos dependentes: famílias e cuidadores. Caderno de Saúde Pública, Rio de Janeiro, 19 (3): 861-866, mai-jun, 2003

72. Caldas, C.P. Envelhecimento com dependência: responsabilidades e demandas da família. Caderno de Saúde Pública, Rio de Janeiro, 19 (3): 773-781, mai-jun, 2003.

73. Silvestre, J. A.; Costa Neto, M. Abordagem do idoso em programas de saúde da família. Cadernos de Saúde Pública, v. 19, n. 3 , RJ, jun. 2003.

74. Veras RP, Alves MIC. A população idosa no Brasil: considerações acerca do uso de indicadores de saúde. In: Minayo, MCS. Os muitos Brasis - Saúde e População na Década de 80 . SP-RJ: Editora HUCITEC; 1.995. 
75. Jogerst, G.J., Daly J.M., Brinig M., Dawson J.D. et al. Domestic Elder Abuse and the Law. American Journal of Public Health, 2.003; 93(12): 2.131-2.136.

76. Hightower J.M.A., Hightower and Associates, Halfmoon Bay, BC. Age, Gender and Violence: Abuse Against Older Women. Geriatrics \& Aging, 2.004; 7(3): 60-63.

77. Krug, E.G. et al. the world report on violence and health. The Lancet, vol 360, october5, 2002, págs. 1083-1088. Disponível em www.thelancet.com

78. Lebrão ML, Duarte YAO. SABE - Saúde, Bem-estar e envelhecimento. O Projeto SABE no município de São Paulo: Uma abordagem inicial. Organização Pan-Americana da Saúde, Brasília, 2003. 


\section{ANEXO A: Comitê de Ética da Faculdade de Saúde Pública da Universidade de São Paulo e Comissão Nacional de Ética em Pesquisa - CONEP}
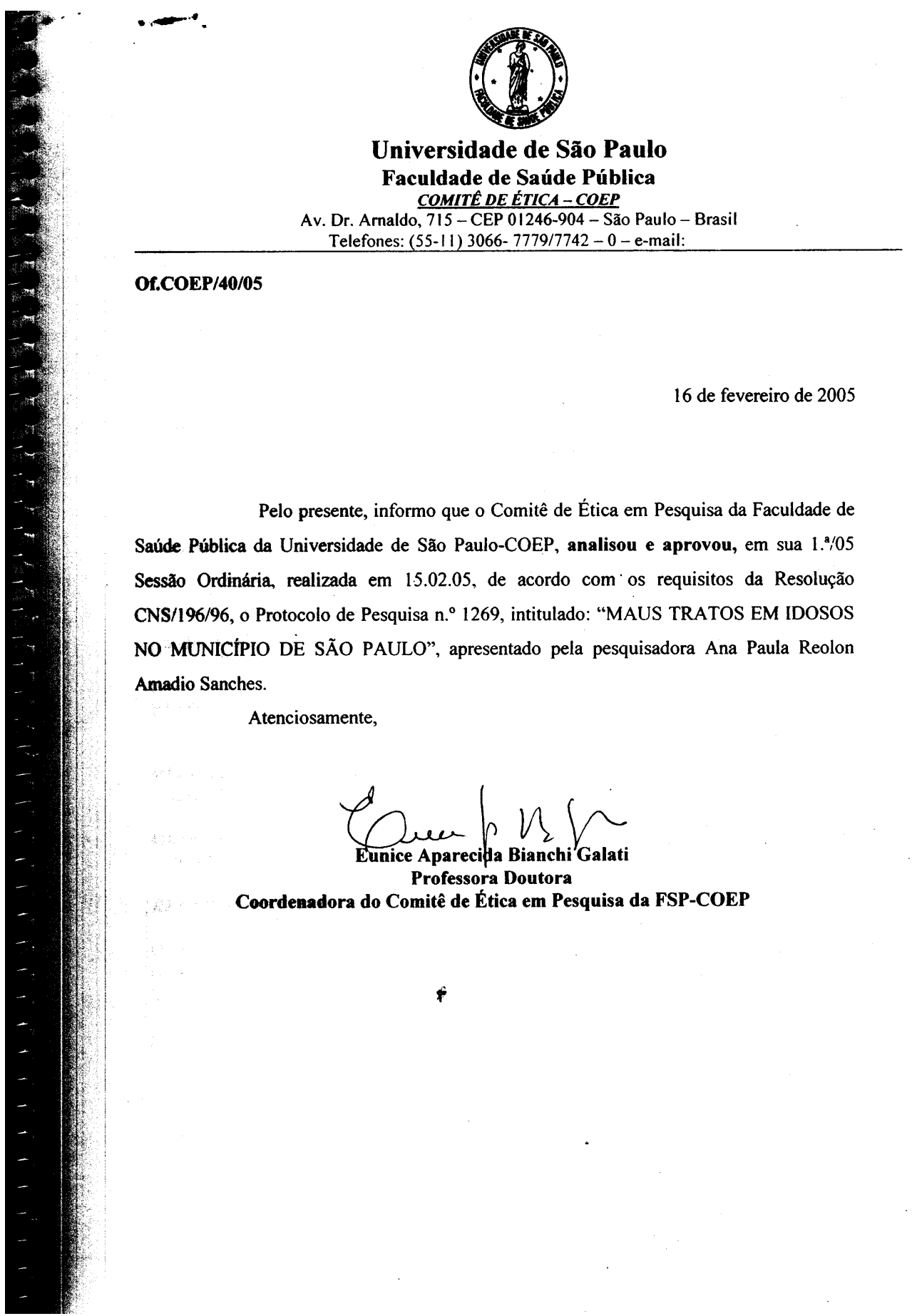

Of.COEP/40/05

16 de fevereiro de 2005

Pelo presente, informo que o Comitê de Ética em Pesquisa da Faculdade de Saúde Pública da Universidade de São Paulo-COEP, analisou e aprovou, em sua $1{ }^{\text {áa }}$ /05 Sessão Ordinária, realizada em 15.02.05, de acordo com os requisitos da Resolução CNS/196/96, o Protocolo de Pesquisa n. ${ }^{\circ} 1269$, intitulado: "MAUS TRATOS EM IDOSOS NO MUNICÍPIO DE SÃO PAULO", apresentado pela pesquisadora Ana Paula Reolon Amadio Sanches.

Atenciosamente,

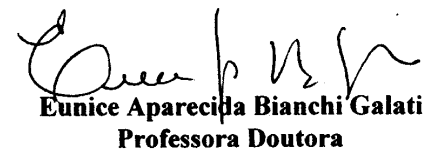

Coordenadora do Comitê de Ética em Pesquisa da FSP-COEP 
ANEXO B: Questionário Estudo SABE

Apresentado sob a forma eletrônica na contra-capa deste exemplar. 